\title{
Impact of Internal Climate Variability on the Relationship between Spring Northern Tropical Atlantic SST Anomalies and Succedent Winter ENSO: The Role of the North Pacific Oscillation 0
}

\author{
SHANGFEng CHEN, ${ }^{\mathrm{a}}$ Wen CHEN, ${ }^{\mathrm{a}}$ BIN Yu, ${ }^{\mathrm{b}}$ AND ZHIBO $\mathrm{LI}^{\mathrm{c}}$ \\ ${ }^{a}$ Center for Monsoon System Research, Institute of Atmospheric Physics, Chinese Academy of Sciences, Beijing, China \\ ${ }^{\mathrm{b}}$ Climate Research Division, Environment and Climate Change Canada, Toronto, Ontario, Canada \\ ${ }^{\mathrm{c}}$ Laboratory for Climate and Ocean-Atmosphere Studies, Department of Atmospheric and Oceanic Sciences, School of Physics, Peking \\ University, Beijing, China
}

(Manuscript received 30 June 2021, in final form 17 September 2021)

\begin{abstract}
Previous studies suggested that spring sea surface temperature anomalies (SSTAs) in the northern tropical Atlantic (NTA) have a marked influence on the succedent winter El Niño-Southern Oscillation (ENSO). In this study, we examine the spring NTA SSTA-winter ENSO connection in a 50-member large-ensemble simulation conducted with the Canadian Centre for Climate Modelling and Analysis second-generation Canadian Earth System Model (CanESM2) and a 100-member ensemble simulation conducted with the Max Planck Institute Earth System Model (MPI-ESM). The observed out-of-phase relation of spring NTA SSTA with winter ENSO can be captured by the multimember ensemble means of the large-ensemble simulations from both models. However, the relation shows a large diversity among different ensemble members attributing to the internal climate variability. The preceding winter North Pacific Oscillation (NPO) is suggested to be an important source of the internal climate variability that modulates the spring NTA SSTA-ENSO connection. The modulation of the winter NPO on the subsequent spring NTA SSTA-winter ENSO relation is seen in both climate modeling and observational datasets. When winter NPO and spring NTA SSTA indices have the same (opposite) sign, the linkage between the spring NTA SSTA and the following winter ENSO tends to be weak (strong). The NPO modulates the spring NTA SSTA-winter ENSO relation mainly via changing the zonal wind anomalies over the tropical western-to-central Pacific induced by the spring NTA SSTA. In addition, our analysis indicates that winter NPO may have a marked effect on the predictability of winter ENSO based on the condition of spring NTA SSTA.
\end{abstract}

KEYWORDS: Atmosphere; Ocean; Pacific Ocean; Teleconnections; ENSO; North Pacific Oscillation; Climate variability; El Nino; La Nina; Climate models; Interannual variability; Tropical variability

\section{Introduction}

El Niño-Southern Oscillation (ENSO) is the most remarkable mode of year-to-year climate variability in the tropical Pacific (Bjerknes 1969; Trenberth et al. 1998; Wang et al. 2000; Alexander et al. 2002; McPhaden et al. 2006; Yeh et al. 2018, and references therein). The occurrence of an ENSO event can exert far-reaching impacts on the global oceanic and atmospheric circulations and lead to frequent occurrences of extreme weather and climate events via teleconnections (Horel and Wallace 1981; Trenberth et al. 1998; Wang et al. 2000; Diaz et al. 2001; Alexander et al. 2002; Wang et al. 2000; Chen et al. 2000; Huang et al. 2004; Dai and Wigley 2000; Chen et al. 2013; He and Wang 2013; Jia et al. 2015; X. Jia et al. 2016; Song et al. 2017; Domeisen et al. 2019; Park and Li 2019; Zheng et al. 2021, and references therein). Global fisheries, agriculture, marine and terrestrial ecosystems, and public health are notably affected by ENSO events (e.g., McPhaden et al. 2006; Yeh et al. 2018; Domeisen et al. 2019). In particular, ENSO-related SSTAs can exert notable impacts on climate

\footnotetext{
OSupplemental information related to this paper is available at the Journals Online website: https://doi.org/10.1175/jcli-d-21-0505.s1.
}

Corresponding author: Wen Chen, cw@post.iap.ac.cn over the North Pacific and North America via a Pacific-North American (PNA) atmospheric teleconnection (Wallace and Gutzler 1981; Yu and Zwiers 2007; Ding et al. 2017; Ma et al. 2018, 2020). Furthermore, ENSO events have a remarkable influence on the occurrence frequency and intensity of tropical cyclones over the tropical Atlantic, Indian, and Pacific Oceans (Gray 1984; Chan 2005; Chen and Li 2018; Quan et al. 2020).

It is well known that the air-sea interaction process within the tropical Pacific is crucial for the onset, development, and transition of ENSO events (Bjerknes 1969; Battisti and Hirst 1989; Suarez and Schopf 1988; Neelin et al. 1998; Jin 1997; Huang et al. 2001; Lengaigne et al. 2004; Anderson and Perez 2015). Besides the physical process in the tropical Pacific, studies suggested that forcings outside the tropical Pacific also play an important role in modulating the onset and evolution of ENSO events (e.g., Vimont et al. 2001, 2003; Anderson 2003; Nakamura et al. 2007; Ham et al. 2013; Ding et al. 2015; Chen et al. 2014, 2018, 2020a; Ding et al. 2017a; Wang et al. 2019; Chen et al. 2020a,c; Park et al. 2021). In particular, recent studies suggested that SSTAs in the northern tropical Atlantic (NTA) in boreal spring could exert significant impacts on the following winter ENSO (Ham et al. 2013; Ham and Kug 2015). Ham et al. (2013) found that spring SST warming (cooling) in the NTA tends to be followed by a La Niña (El Niño) event in the following winter. Specifically, spring NTA warm (cold) SSTAs could induce strong easterly 
(westerly) wind anomalies in the tropical western-to-central Pacific in the following summer via an atmospheric teleconnection process, which further impact a succeeding winter La Niña (El Niño) event (Ham et al. 2013). Studies indicated that considering SST conditions in the tropical Atlantic could provide an additional useful source for the prediction of winter ENSO (Keenlyside et al. 2013; Ham et al. 2013; MartínRey et al. 2015; Chikamoto et al. 2015; Kucharski et al. 2016). In addition to NTA SSTAs, studies also reported that the Atlantic Niño and SSTAs in the North Atlantic have a prominent impact on the ENSO and Pacific decadal variability (e.g., Rodríguez-Fonseca et al. 2009; Kucharski et al. 2011; Ding et al. 2012; Li et al. 2015; Ruprich-Robert et al. 2017; Park et al. 2019; Chikamoto et al. 2020; Johnson et al. 2020).

On the other hand, the connection of the spring NTA SSTA with the following winter ENSO is unstable, and it experienced a marked interdecadal change around the late 1970s. In particular, Chen and $\mathrm{Wu}$ (2017) show that the significant influence of the spring NTA SSTA on the winter ENSO can only be observed after the late 1970s. In addition to the NTA SSTA, recent studies also found that the connection between other tropical Atlantic SST variability modes (such as the Atlantic Niño) and the tropical Pacific climate tends to be enhanced after the 1970s (e.g., Martín-Rey et al. 2014, 2018; Wang et al. 2017). Several studies demonstrated that the recent enhancement of the connection between the tropical Atlantic SSTA and the tropical Pacific climate could not be explained by the external forcing related to the anthropogenic greenhouse warming. Instead, the anthropogenic greenhouse warming-related external forcing tends to bring a weakened impact of the tropical Atlantic SSTA on the winter ENSO and associated tropical Pacific climate anomalies (F. Jia et al. 2016; Jia et al. 2019). Results in these previous studies imply that the internal climate variability could exert substantial impacts on the connection between the tropical Atlantic SSTA and tropical Pacific climate variability. However, it remains unclear what the main sources of the internal climate variability are that affect the relationship between spring NTA SSTA and following winter ENSO.

Recently, large-ensemble simulations conducted with coupled climate models are employed to explore climate variability and climate change projections (e.g., Deser et al. 2012, 2014; Wallace et al. 2015; Dai and Bloecker 2019; Chen et al. 2019; Yu et al. 2020; Chen and Yu 2020; Piao et al. 2021). Based on single-model initial-condition large-ensemble simulations, one can investigate the impact of internal climate variability on the connection between various climate components (Chen and $\mathrm{Yu}$ 2020), and climate change projections (Deser et al. 2012, 2014; Kirchmeier-Young et al. 2017; Yu et al. 2020; Piao et al. 2021).

In this study, we first examine whether the significant linkage between the spring NTA SSTA with the succedent winter ENSO as obtained in the observation (Ham et al. 2013) can be captured in large-ensemble climate simulations. We analyzed the spring NTA SSTA-winter ENSO connection in a 50-member ensemble simulation conducted with the Canadian Centre for Climate Modelling and Analysis (CCCma) second-generation Canadian Earth System Model (CanESM2; Sigmond and Fyfe 2016) and a 100-member ensemble simulation conducted with the Max Planck Institute Earth System Model (MPI-ESM; Maher et al. 2018; 2019). Each member of the CanESM2/MPIESM simulations is driven by a same external forcing but with a slightly different initial condition, which will be described in section 2. Hence, the diversity of the spring NTA SSTA-winter ENSO relation among the 50 members of CanESM2 and the 100 members of MPI-ESM is attributed solely to the internal climate variability (Deser et al. 2012, 2014; Wallace et al. 2015). The second goal of the present study is to explore the source of the internal climate variability that influences the connection of the spring NTA SSTA and winter ENSO based on these ensemble climate simulations. In particular, the physical process for the impact of the internal climate variability will be investigated. We will also use observational data to confirm the impact of the internal climate variability, as obtained from the large-ensemble simulations, on the spring NTA SSTA-winter ENSO relation. Finally, we explore impacts of the internal climate variability on the predictability of ENSO based on the spring NTA SSTA.

The rest of the paper is organized is follows: section 2 describes the data and methods used in the present analysis. Section 3 examines the linkage of the spring NTA SST with the following winter ENSO in the observations and in the large-ensemble simulations of the CanESM2 and MPI-ESM. Section 4 explores the impact of the internal climate variability on the diversity of the spring NTA SSTA-winter ENSO connection and highlights the influence of the winter NPO on this relationship. The modulation influence of the NPO on the spring NTA SSTA-winter ENSO connection is also confirmed using observational data, as descried in section 5 . Section 6 summarizes the key findings of this study and provides several discussions.

\section{Data and methods}

\section{a. Observational data}

The monthly mean geopotential height, horizontal winds, and precipitation data are extracted from the National Centers for Environmental Prediction (NCEP)-National Center for Atmospheric Research (NCAR) reanalysis dataset from 1948 to the present (Kalnay et al. 1996; https://psl.noaa.gov/ data/reanalysis/reanalysis.shtml). Atmospheric variables from the NCEP-NCAR reanalysis have 17 pressure levels extending from 1000 to $10 \mathrm{hPa}$, and are on $2.5^{\circ} \times 2.5^{\circ}$ horizontal longitude-latitude grids. Precipitation from the NCEP-NCAR reanalysis has a horizontal resolution of T62 Gaussian grids (Kalnay et al. 1996). We use two monthly mean SST datasets, including 1) the National Oceanic and Atmospheric Administration (NOAA) Extended Reconstructed SST version 5 dataset (ERSSTV5; Huang et al. 2017; https://psl.noaa.gov/ data/gridded/data.noaa.ersst.v5.html) and 2) the Hadley Center Global Sea Ice and Sea Surface Temperature dataset (HadISST; Rayner et al. 2003; https://www.metoffice.gov.uk/ hadobs/hadisst/). ERSSTV5 SST dataset has a horizontal resolution of $2^{\circ} \times 2^{\circ}$ and available from January 1854 to the present (Huang et al. 2017). HadISST SST dataset has a horizontal resolution of $1^{\circ} \times 1^{\circ}$ and available from January 
1870 to the present (Rayner et al. 2003). In this study, atmospheric data derived from the NCEP-NCAR reanalysis and SST data from the ERSSTV5 and HadISST are referred to as "observational data" for convenience of descriptions and comparisons.

\section{b. Large-ensemble climate model simulations}

We use a 50-member large-ensemble climate simulation of the CanESM2 (Sigmond and Fyfe 2016; Yu et al. 2020). CanESM2 is a fully coupled atmosphere-ocean-land-sea ice climate model (Arora et al. 2011; Kirchmeier-Young et al. 2017; Chen and Yu 2020). The 50-member largeensemble simulations are described as follows. First, five experiments are run over the period of 1850-1950 to form five oceanic states in 1950 with slight differences. Second, 10 simulations are performed for the period of 1950-2100 at each of the above five experiments with small initial state differences in 1950. This results in a total of 50 ensemble members simulations. Note that small differences in the initial states in 1950 could result in variant atmospheric conditions after several days attributing to chaotic nature of the climate system (Deser et al. 2012; Kay et al. 2015). From 1950 to 2005 , each of the 50 simulations is run by the historical greenhouse gas concentration, solar radiation, aerosols, volcanic eruption, land use, etc., similar with that performed in the CMIP5 simulations (Christian et al. 2010; van Vuuren et al. 2011; Sigmond and Fyfe 2016; Chen and Yu 2020). From 2006 to 2100 , each of the simulations is forced by the representative concentration pathway 8.5 (RCP8.5; van Vuuren et al. 2011). The CanESM2 simulations have a $2.8^{\circ} \times 2.8^{\circ}$ horizontal resolution.

To confirm the results obtained from CanEMS2, we also use a 100-member large-ensemble historical simulation conducted with the MPI-ESM (Maher et al. 2018, 2019). MPIESM is also a fully coupled atmosphere-ocean-land-sea ice climate model with a horizontal resolution of about $1.9^{\circ} \times$ $1.9^{\circ}$ in the longitude-latitude grids (Maher et al. 2018, 2019). In the present study, results obtained from the CanESM2 and MPI-ESM simulations are similar. Hence, in the following, we mainly show the results from CanEMS2 unless otherwise stated.

\section{c. Methods}

All data from the observations (i.e., NCEP-NCAR reanalysis, ERSSTV5 and HadISST SST), CanESM2 and MPI-ESM simulations are interpolated to a common $2.5^{\circ} \times 2.5^{\circ}$ longitude-latitude grid to calculate multimember ensemble mean (MME) and pattern correlations. MME is calculated as the mean of the members considered. Previous studies have demonstrated that the relationship of the spring NTA SSTA with the following winter ENSO is weak before the late 1970s (Chen and Wu 2017; Martín-Rey et al. 2018). Thus, this study focuses on the period after 1979 (i.e., 1979-2005) when comparing the CanESM2 and MPI-ESM historical simulations with the observations. It should be mentioned that very similar results can be obtained if based on the data of CanESM2 and MPI-ESM historical simulations before the late 1970s (not shown).

Anomalies are calculated by subtracting climatology in each month for the period of 1979-2005. This study examines the interannual relationship between the spring NTA SSTA and winter ENSO. Therefore, a 2-9-yr Lanczos bandpass filter is applied to all data to remove their interdecadal components and long-term trends following previous studies (Duchon 1979; Chen et al. 2015, 2020b). It is well known that winter ENSO has a prominent quasi-biennial oscillation (i.e., winter SSTA in the tropical central-to-eastern Pacific has a significant negative correlation with that in the following winter) (Neelin et al. 1998; Yeh et al. 2018), and a significant impact on the succedent spring SSTA in the NTA (Curtis and Hastenrath 1995; Wang et al. 2000; Czaja et al. 2002; Alexander et al. 2002; Chen et al. 2015). In particular, an El Niño (La Niña) event in boreal winter tends to be followed by marked positive (negative) SSTAs in the NTA in the subsequent spring (Curtis and Hastenrath 1995; Alexander et al. 2002; Chen et al. 2015). Hence, to isolate the contribution of the ENSO cycle to the spring NTA SSTA-following winter ENSO connection, the preceding winter ENSO signal has been linearly removed from the spring NTA SST index and all other variables. Following previous studies (Chen et al. 2014; Zhao et al. 2019), the winter ENSO signal is represented by the Niño-3.4 SST index, which is defined as an area-mean SSTA over the region of $5^{\circ} \mathrm{S}-5^{\circ} \mathrm{N}, 120^{\circ}-170^{\circ} \mathrm{W}$.

Significance levels of regression and correlation coefficients calculated in each member of the CanEMS2 and MPI-ESM simulations, and those in the observations are assessed based on the two-tailed Student's $t$ test. As there exists autocorrelation of climate variability, the effective degree of freedom $\left(\mathrm{DOF}_{E}\right)$ is considered and calculated according to the method of Bretherton et al. (1999). Following Bretherton et al. (1999), $\mathrm{DOF}_{E}$ is expressed as follows:

$$
\mathrm{DOF}_{E}=N \times\left(\frac{1-r_{1} r_{2}}{1+r_{1} r_{2}}\right)-2 .
$$

Here, $N$ represents the number of year, and $r_{1}$ and $r_{2}$ indicate the lag-1-yr autocorrelation coefficients of the two time series.

As in Deser et al. (2012), Joshi and Ha (2019), and Chen and $\mathrm{Yu}$ (2020), MME anomalies of regression coefficients are statistically significant at the $95 \%$ confidence level if it meets the following criterion:

$$
|\mathrm{MME}| \geq \frac{\gamma \times \mathrm{STD}}{\sqrt{N}},
$$

where $|\mathrm{MME}|$ is the absolute value of the MME anomaly, $\gamma$ is a constant (equal to 1.96), $N$ is the number of members used in the composite analysis, and STD indicates the standard deviation of anomalies among the members considered.

In the present study, significance of the difference between two correlation coefficients is estimated based on the "Fisher's $r$-to- $z$ transformation" technique (Fisher 1921; Chen et al. $2015,2020 b$ ). First, the two correlation coefficients (i.e., $r_{1}$ and $\left.r_{2}\right)$ are transformed following the equations below: 

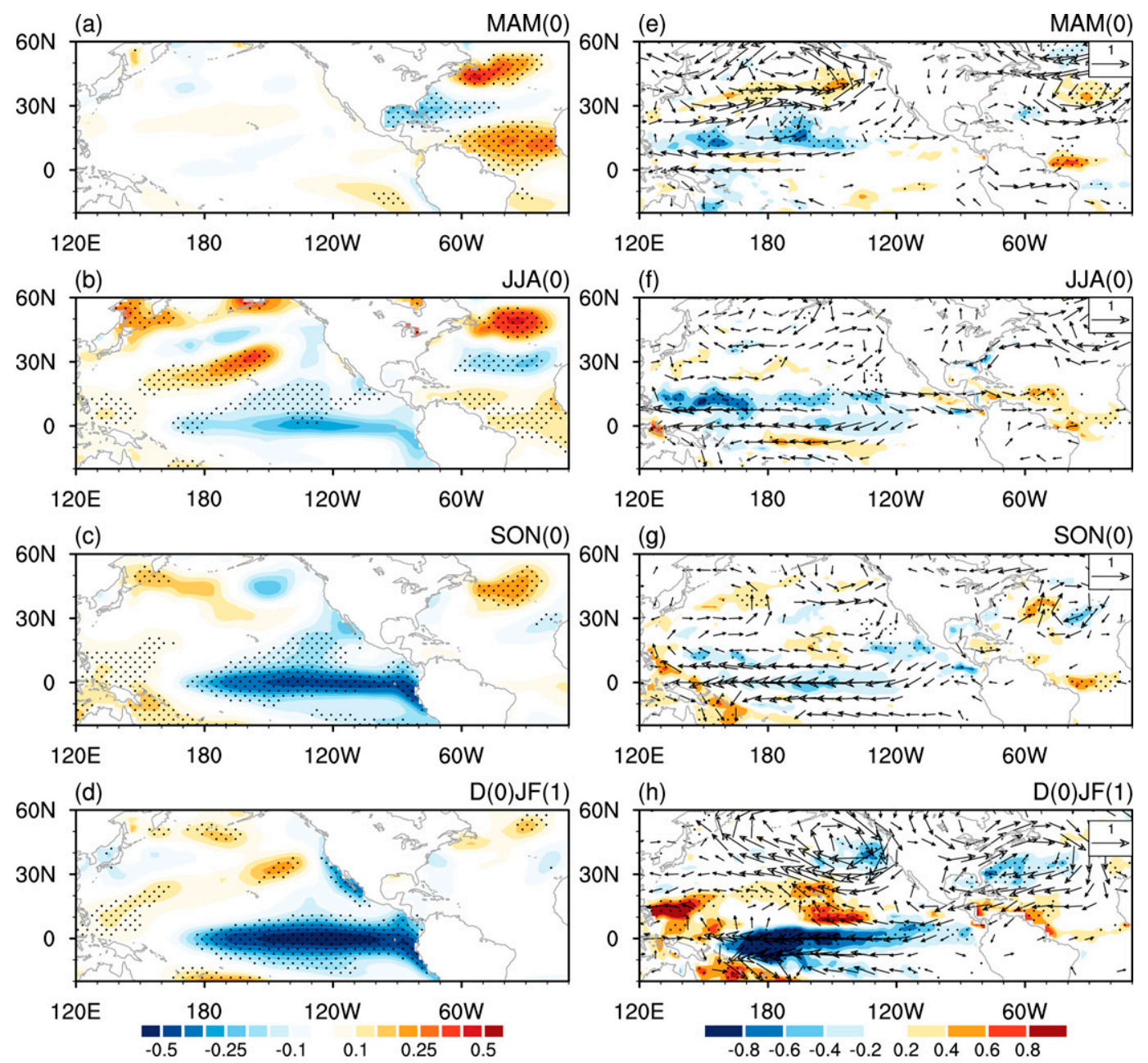

FIG. 1. Anomalies of (a)-(d) SST and (e)-(h) precipitation (shading) and 850-hPa winds (vectors) in (a),(e) $\operatorname{MAM}(0)$; (b),(f) JJA(0); (c),(g) SON(0); and (d),(h) D(0)JF(1) regressed upon the normalized MAM(0) NTA SST index over 1979-2005 in the observations. Stippled regions in (a)-(d) and (e)-(h) indicate SST and precipitation anomalies, respectively, significant at the $95 \%$ confidence level. Units of SST, precipitation, and winds are ${ }^{\circ} \mathrm{C}, \mathrm{mm}$ day $^{-1}$, and $\mathrm{m} \mathrm{s}^{-1}$, respectively.

$$
\begin{aligned}
& Z_{1}=0.5 \times \ln \left(\frac{1+r_{1}}{1-r_{1}}\right), \\
& Z_{2}=0.5 \times \ln \left(\frac{1+r_{2}}{1-r_{2}}\right) .
\end{aligned}
$$

Second, the standard parametric test is employed to estimate the null hypothesis of the equality of $Z_{1}$ and $Z_{2}$. Third, the test statistic $u=\left(Z_{1}-Z_{2}\right) /\left[\sqrt{1 /\left(N_{1}-3\right)}+\sqrt{1 /\left(N_{2}-3\right)}\right]$ satisfies the normal distribution (Fisher 1921), where $N_{1}$ and $N_{2}$ are the number of the years employed to calculate $r_{1}$ and $r_{2}$, respectively.

\section{Relation of the spring NTA SSTA with succedent winter ENSO}

In this section, we first examine the connection of the spring NTA SSTA with the following winter ENSO based on the

observational data. Then, we check this spring NTA SSTAsuccedent winter ENSO relation in the large-ensemble simulations.

Figure 1 shows evolutions of SST, precipitation, and 850$\mathrm{hPa}$ wind anomalies from spring $[\mathrm{MAM}(0)]$ to the following winter $[\mathrm{D}(0) \mathrm{JF}(1)]$ regressed upon the MAM(0) NTA SST index for the period of 1979-2005. In the present study, the time notations of $(-1),(0)$, and (1) denote the years before, during and after the spring NTA SSTA. For a positive phase of the $\operatorname{MAM}(0)$ NTA SST index, in $\operatorname{MAM}(0)$, a tripolar SSTA pattern is apparent in the North Atlantic, with pronounced positive SSTAs in the NTA and midlatitude North Atlantic around $40^{\circ}-50^{\circ} \mathrm{N}$, together with significant negative SSTAs in the subtropical northwestern Atlantic (Fig. 1a). A significant increase in precipitation (indicating enhanced atmospheric heating) is seen over the NTA as a response to the SST warming there (Figs. 1a,e), especially off the west coast of South America where the climatology intertropical 

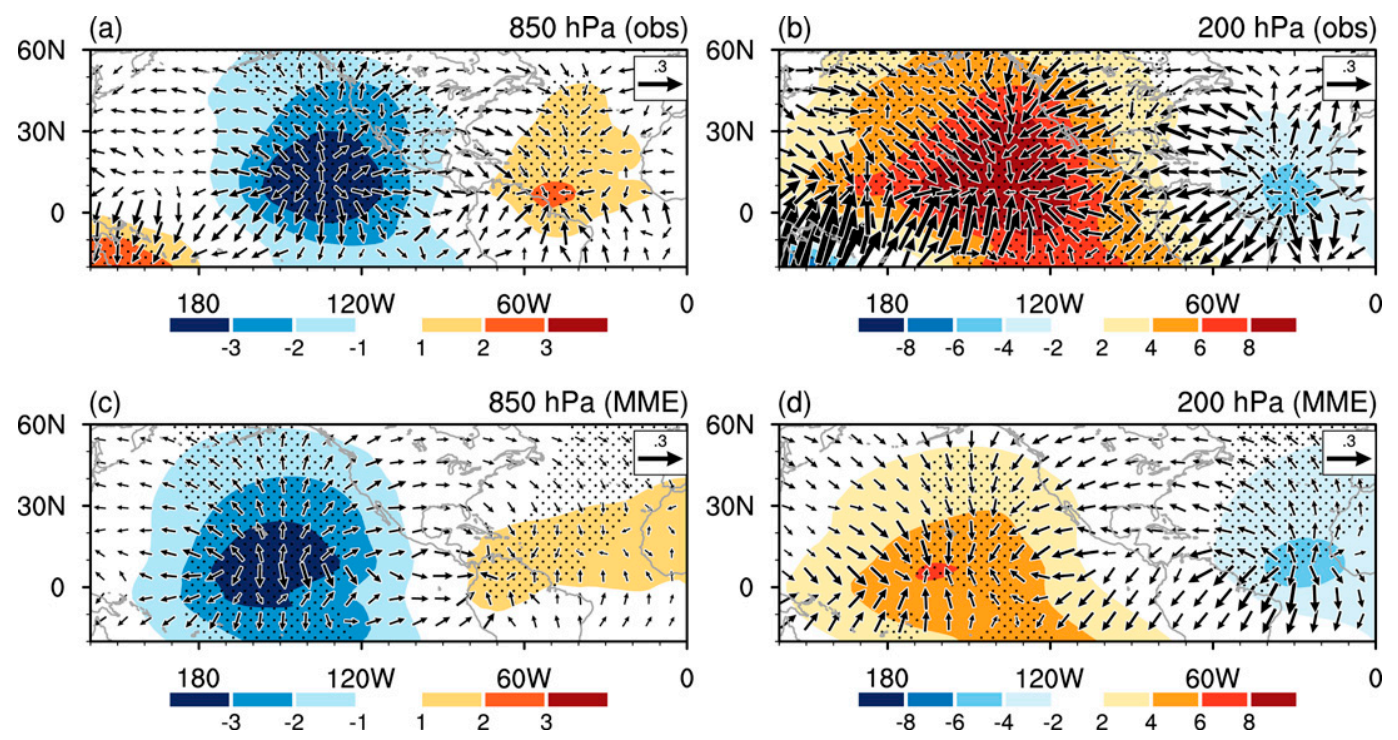

FIG. 2. Anomalies of velocity potential (shading, unit: $10^{5} \mathrm{~m}^{2} \mathrm{~s}^{-1}$ ) and divergent winds (vectors, unit: $\mathrm{m} \mathrm{s}^{-1}$ ) at (a) 850 and (b) $200 \mathrm{hPa}$ in JJA(0) regressed upon the normalized MAM(0) NTA SST index over 1979-2005 in the observations. (c),(d) As in (a) and (b), but for ensemble mean of the 50 members of CanESM2. Stippled regions indicate velocity potential anomalies significant at the $95 \%$ confidence level.

convergence zone (ITCZ) is located. Associated with the above SSTA pattern, a meridional dipole atmospheric anomaly pattern appears over the North Atlantic, with an anomalous cyclone over subtropics and an anomalous anticyclone over midlatitude (Fig. 1e), a reminiscent of the negative phase of the North Atlantic Oscillation (NAO; Hurrell and van Loon 1997). Ham et al. (2013, their Fig. 1a) indicated that a significant cyclonic anomaly could be induced over the subtropical northwestern Atlantic and northeastern Pacific as a response to the SST warming in the NTA, accompanied by strong northeasterly wind anomalies over the subtropical northeastern Pacific and westerly wind anomalies over the tropical eastern Pacific. The cyclonic anomaly over the subtropical northeastern Pacific seen in our study (Fig. 1e) is much weaker compared to that in Ham et al. (2013), which may be related to the different period analyzed. In addition, anomalous fields have been subjected to a 2-9-yr high-pass filter to obtain their interannual components in the present analysis, as we focus on examining interannual relationship between spring NTA SSTA and following winter ENSO. In contrast, Ham et al. (2013) only removed long-term trends, while interdecadal components of all variables are retained. This difference may also contribute to differences in the atmospheric anomalies over subtropical northeastern Pacific related to the spring NTA SSTA between this analysis and that in Ham et al. (2013).

The North Pacific is dominated by a meridional dipolar atmospheric anomaly pattern, with a cyclonic anomaly over midlatitudes and an anticyclonic over the subtropics (Fig. 1e). In the simultaneous spring, SSTAs in the North Pacific are quite weak (Fig. 1a), indicating the formation of the North Pacific dipolar atmospheric anomaly is not likely due to the underlying SSTA. Park et al. (2019) indicated that SSTAs in the North Atlantic could induce notable atmospheric anomalies over the North Pacific via triggering atmospheric Rossby wave train. In addition, whether the spring NAO plays a role in connecting the spring NTA SSTA with the spring NPO-like atmospheric anomalies over the North Pacific is still unknown. To address this issue, we have calculated the correlation coefficient of the spring NPO index with the spring NAO index, as well as the correlation coefficient between the spring NAO index and the spring NTA SST index. It is found that spring NTA SST index has a significant correlation with the spring NAO index over 1979-2005, with a correlation of -0.43 significant at the $95 \%$ confidence level. Correlation coefficient of the spring NAO index with the spring NPO index is 0.28 , which cannot pass the $95 \%$ confidence level. This suggests that spring NAO cannot explain formation of the dipole atmospheric anomaly over the North Pacific related to the spring NTA SSTA.

The tripole SSTA pattern in the North Atlantic can maintain to the following summer, which is due to the interaction between Atlantic SSTAs and the overlying NAO-like atmospheric anomalies (Wu and Liu 2005; Peng et al. 2003; Huang and Shukla 2005; Pan 2005; Chen et al. 2015, 2020b; Yang and $\mathrm{Wu}$ 2015). Studies indicated that NAO-like atmospheric anomalies lead to a tripolar SSTA pattern via modulating surface heat fluxes (Wu and Liu 2005; Huang and Shukla 2005; Chen et al. 2015, 2020b). SSTAs in the North Atlantic, in turn, contribute to a NAO-like pattern via a Rossby wavetype atmospheric response and the wave-mean flow interaction process (Peng et al. 2003; Pan 2005; Chen et al. 2015, 2020b). Positive SSTAs in JJA(0) in the NTA are accompanied by significant increase in precipitation there, which could induce an anomalous tropical Walker circulation, with upward motion anomalies over the NTA (indicated by convergent anomalies at the lower troposphere and divergent anomalies at the upper troposphere; Figs. 2a,b), and downward motion anomalies in the tropical central Pacific (indicated by divergent 
anomalies at the lower troposphere and convergent anomalies at the upper troposphere; Figs. 2a,b) (please also see Fig. S1 in the online supplemental material for the vertical circulation anomalies). Subsequently, the downward motion anomalies over the tropical central Pacific and associated decrease in the atmospheric convection contribute to easterly wind anomalies over the tropical western-to-central Pacific (Fig. 1f). Previous studies have demonstrated that easterly wind anomalies over the tropical western-to-central Pacific could lead to SST cooling in the tropical central-to-eastern Pacific via triggering eastward propagating equatorial upwelling Kelvin waves (Huang et al. 2001; Nakamura et al. 2006, 2007; Ham et al. 2013; Chen et al. 2014). The negative SSTA in the tropical central-to-eastern Pacific suppresses atmospheric heating there, and maintains easterly wind anomalies over the tropical western-tocentral Pacific via reducing tropical zonal SST and SLP gradient (Figs. 1b-g), forming a positive Bjerknes-like air-sea feedback (Bjerknes 1969). Finally, a La Niña-like SST pattern is induced in the following winter (Figs. 1d-h). The above analysis suggests that positive (negative) SSTAs in the NTA in spring are favorable for the occurrence of a La Niña (El Niño) event in the succedent winter, consistent with previous studies (Ham et al. 2013; Ham and Kug 2015; Wang et al. 2017).

Previous studies indicated that the positive spring NTA SSTA-induced SST cooling in the following winter tends to be in the central equatorial Pacific, resembling the central Pacific (CP) type of La Niña (Ham et al. 2013; Ham and Kug 2015; Wang et al. 2017). From Fig. 1d, it shows that significant negative SST anomalies can extend to the equatorial eastern Pacific. This indicates that spring NTA SST anomalies also have a notable impact on the eastern Pacific (EP) type of ENSO events. We have examined the spring NTA SST index over 1979-2005 ( Fig. S2). From Fig. S2, three EP type of E1 Niño events (i.e., 1982/83, 1986/87, 1997/98) are preceded by anomalous negative spring NTA SST index ( Fig. S2). In addition, three EP types of La Niña events after the late 1970s (i.e., 1984/85, 1995/96, and 2005/06; Song et al. 2017) are preceded by strong positive spring NTA SST index ( Fig. S2). Furthermore, previous studies have indicated that CP type of ENSO events occurred more frequently after the late 1990s. However, impact of the spring NTA SST anomalies on the following winter ENSO have become significant after the late 1970s (Chen and Wu 2017; Wang et al. 2017; Jia et al. 2019). The above evidence collectively indicates that spring NTA SSTA cannot only impact the CP type ENSO, but also the EP-type ENSO.

Next, we evaluate the performance of the CanESM2 largeensemble simulations in reproducing the spring NTA SSTA-subsequent winter ENSO relationship. Before examining this connection, we check the ability of the CanESM2 simulations in reproducing spatial patterns of the spring SSTA in the NTA related to the spring NTA SST index, as well as characteristics of the ENSO cycle, including its seasonal phaselocking feature and spatial pattern of SSTA during its peak phase (i.e., boreal winter).

Figure 3a shows the seasonal evolution of monthly standard deviations of the Niño-3.4 SST index for the 50 members of CanEMS2 and their MME. All members can well capture the (a)

Nino-3.4 Monthly stdd



(b)

ENSO pattern corr

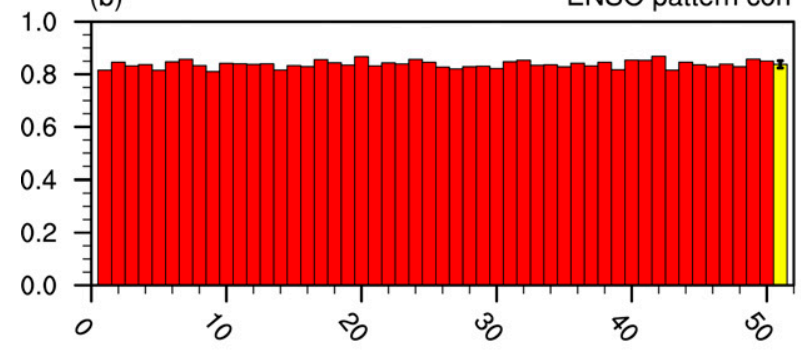

(c)

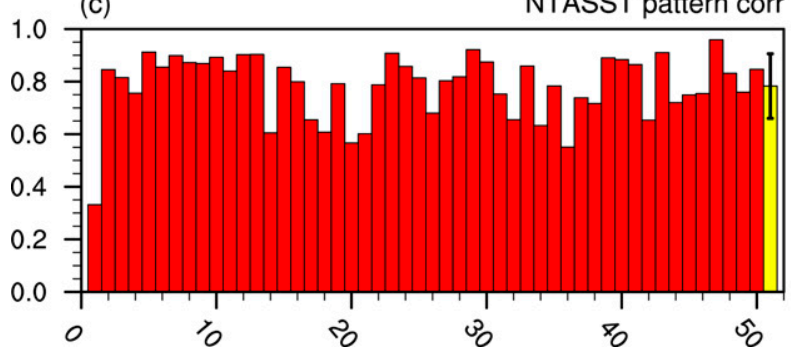

FIG. 3. (a) Standard deviations (unit: ${ }^{\circ} \mathrm{C}$ ) of the monthly Niño3.4 SST index for the 50 members of the CanESM2 (thin gray lines) and their MME (thick blue line). The red line indicates the observed result. (b) Pattern correlation coefficients of winter Niño3.4 SST index related winter SSTA over $30^{\circ} \mathrm{S}-30^{\circ} \mathrm{N}, 100^{\circ} \mathrm{E}-70^{\circ} \mathrm{W}$ in the observation and the 50 members of CanESM2. Yellow bar indicates MME of the 50 members. Error bar represents one standard deviation of the correlation coefficients among the $50 \mathrm{mem}$ bers. (c) As in (b), but for pattern correlation coefficients of spring NTA SST index related spring SSTA over $0^{\circ}-30^{\circ} \mathrm{N}, 0^{\circ}-70^{\circ} \mathrm{W}$ in the observation and the 50 members of CanESM2.

phase-locking feature of ENSO, with the maximum standard deviation of the Niño-3.4 SST index in boreal winter, consistent with that in the observation (Fig. 3a, red curve). Note that the minimum standard deviation of the monthly Niño-3.4 SST index occurs in April in the observation, while it appears in May for the MME of the 50 members of CanEMS2 (Fig. 3a) (i.e., one month delayed compared to observations). We have also compared spatial distributions of the winter SSTA anomalies regressed upon the winter Niño-3.4 SST index in the observation and CanEMS2 simulations (see Fig. S3). CanESM2 can well capture the spatial pattern of the winter SSTA in the tropical Pacific related to the ENSO ( Fig. S3). In particular, the pattern correlation coefficients between the winter SSTA related to the winter Niño-3.4 SST index over the region of $30^{\circ} \mathrm{S}-30^{\circ} \mathrm{N}, 100^{\circ} \mathrm{E}-70^{\circ} \mathrm{W}$ in the observation and the $50 \mathrm{mem}-$ bers are larger than 0.8 (Fig. 3b). Overall, CanEMS2 has a good 

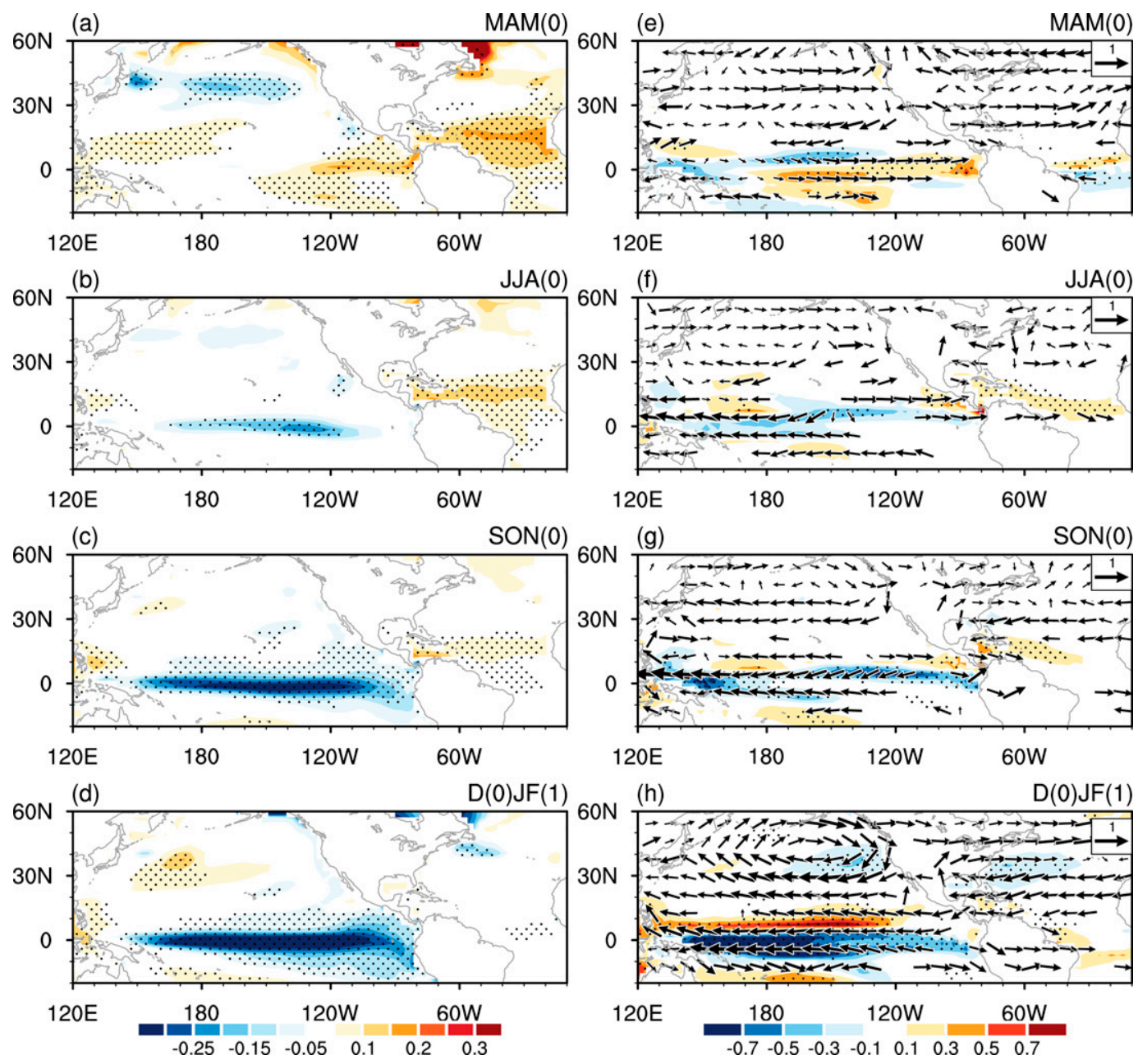

FIG. 4. As in Fig. 1, but for ensemble mean of the 50 members of CanESM2.

performance in simulating the ENSO variability. Figure S4 shows regression maps of SSTAs in spring onto the normalized spring NTA SST index for the 50 members of CanESM2 and their MME. Most members can well reproduce the observed spatial pattern of SSTA in the NTA, with the pattern correlations over $0^{\circ}-30^{\circ} \mathrm{N}, 0^{\circ}-70^{\circ} \mathrm{W}$ larger than 0.6 (except member one) (Fig. 3c). This suggests that the CanEMS2 simulations can also reasonably well reproduce the spatial pattern of the spring NTA SSTA.

We then examine the connection of the spring NTA SST with the following winter ENSO for the MME of the CanESM2 simulations for the period of 1979-2005. Figure 4 exhibits 3-month averages of SST, 850-hPa winds, and precipitation anomalies from $\mathrm{MAM}(0)$ to $\mathrm{D}(0) \mathrm{JF}(1)$ regressed upon the normalized MAM(0) NTA SST index for the MME. In MAM(0), significant positive SSTAs appear in the NTA, and maintain to the following autumn [SON(0)] (Figs. $4 \mathrm{a}-\mathrm{c}$ ). This suggests that the spring NTA SST-related SSTA in the NTA persists longer in CanESM2 compared to that in the observation. MME tends to underestimate the spring North Atlantic tripolar pattern, with much weaker negative SSTAs in the subtropical western North Atlantic and weaker positive anomalies in the midlatitudes (Fig. 4a) compared to the observed (Fig. 1a). Similar to the observation (Fig. 1e), a NAO-like atmospheric anomaly occurs in the North Atlantic and a North Pacific Oscillation-like (NPO; Linkin and Nigam 2008; Song et al. 2016a) atmospheric anomaly appears in the North Pacific (Fig. 4e). Significant negative SSTAs are seen in the midlatitude North Pacific around $40^{\circ} \mathrm{N}$ (Fig. 4a), which may be due to the anomalous westerly winds there (Fig. 4e). The circulation anomalies over midlatitudes would enhance the westerly wind speed, leading to an enhancement of upward latent heat flux (not shown) and SST cooling (Fig. 4a). By contrast, the anomalous westerly winds over the tropical eastern Pacific oppose the climatological easterly wind, reduce the total wind speed, and contribute to SST warming there via reducing surface evaporation (Figs. 4a,e).

In $\operatorname{JJA}(0)$, SST warming in the NTA results in enhanced atmospheric heating there (indicated by significant positive precipitation anomalies). Similar to the observation, an increase in the atmospheric heating over the NTA would induce a tropical zonal overturning circulation, with upward 
(a)

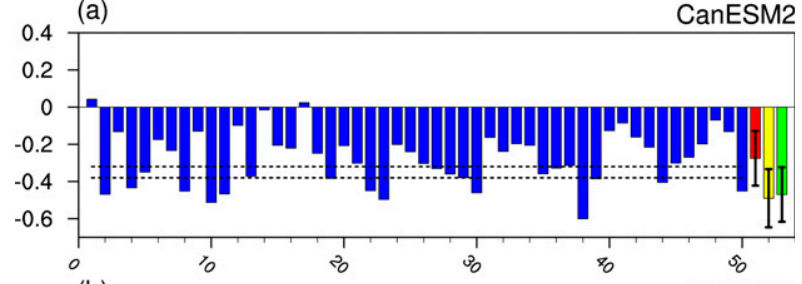

(b)

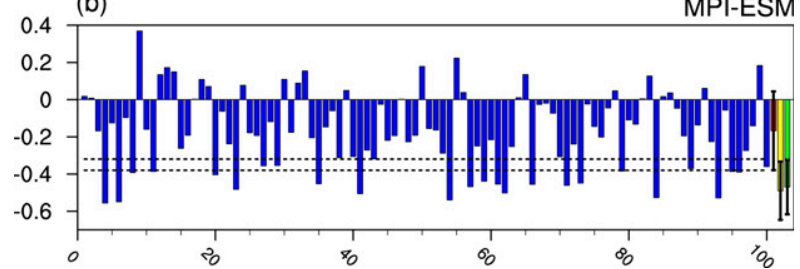

FIG. 5. (a) Correlation coefficients between the spring NTA SST index and succedent winter Niño-3.4 SST index over period of 1979-2005 for the 50 members of the CanESM2 (blue bars), and their MME (red bar) with error bar indicating one standard deviation of the correlations among the 50 members. (b) As in (a), but from the 100 members of the MPI-ESM. Horizontal dashed lines indicate the correlation in individual member significant at the $90 \%$ and $95 \%$ confidence levels, respectively. The yellow and green bars in (a) and (b) indicate the results from the ERSSTv5 and HadISST over 1979-2005, with the overlying error bars representing one standard deviation of the correlation coefficients calculated in a 27-yr moving window over a longer period. ERSSTv5 (HadISST) corresponds to 1854 (1870) to the present in calculating the error bar.

motion anomalies in the NTA (associated with anomalous convergence at the lower troposphere and divergence at the upper troposphere) and downward motion anomalies in the tropical central Pacific (associated with anomalous divergence at the lower troposphere and convergence at the upper troposphere) (Figs. 2c,d). At the lower troposphere, the downward motion anomalies in the tropical central Pacific are accompanied by easterly wind anomalies to its west side over the tropical western-to-central Pacific (Fig. 4f). Subsequently, the lowlevel easterly wind anomalies over the tropical western-tocentral Pacific contribute to SST cooling in the tropical central-to-eastern Pacific via stimulating eastward moving equatorial cold Kelvin waves (Huang et al. 2001; Nakamura et al. 2006; Ham et al. 2013; Chen et al. 2018). Via the Bjerknes positive air-sea feedback process (Bjerknes 1969), the negative SSTA in the tropical central-to-eastern Pacific maintains and develops to a La Niña event (Fig. 4d). The above analysis indicates that MME of the CanESM2 simulations can reasonably well reproduce the observed significant connection of the spring NTA SSTA with the following winter ENSO.

We have also examined the spring NTA SSTA-winter ENSO relation in each of the CanESM2 simulations. Figure 5 shows correlation coefficients between the spring NTA SST index and succedent winter Niño-3.4 SST index over 1979-2005 for the 50 members and their MME. The correlation coefficients between the spring NTA SST index and the winter Niño-3.4 SST index obtained from the ERSSTV5 and HadISST are -0.49 (yellow bar) and -0.47 (green bar), respectively, which are comparable and both significant at the $95 \%$ confidence level. Forty-eight out of the 50 members can reproduce the observed out of phase relation of the spring NTA SST index and the winter Niño-3.4 index. The MME of correlation coefficients is -0.27 (red bar), about half of that in the observation (Fig. 5). However, the observed correlation coefficient between the two indices is within the range of the 50 members. For the individual members, 20 (11) out of the 50 simulations produce a significant negative relation of the spring NTA SST index and the winter Niño-3.4 SST index passing the $90 \%$ (95\%) confidence level (Fig. 5, dashed lines). Nevertheless, two members even produce weak positive correlations of spring NTA SSTA with the winter Niño-3.4 SST index. The above evidence suggests that there exists a large diversity in the spring NTA SSTA-subsequent winter ENSO connection among the 50 ensemble members. Since the 50-member large-ensemble simulations of CanESM2 are forced by the same external forcing, the diversity of the spring NTA SSTA-winter ENSO relationship among the different ensemble members is attributed solely to the internal climate variability (Deser et al. 2012; Wallace et al. 2015; Chen et al. 2019; Chen and Yu 2020). Hence, the internal climate variability is suggested to exert a notable impact on the spring NTA SSTA-winter ENSO relationship.

Standard deviation of the correlation coefficient between the spring NTA SST index and the winter Niño-3.4 SST index among the 50 members is 0.15 . We have also calculated uncertainty of the spring NTA SSTA-winter ENSO connection in the ERSSTV5 and HadISST, which is defined as the standard deviation of the correlation coefficient calculated in a $27-\mathrm{yr}$ moving window across a longer period. It shows that standard deviations of the correlation coefficient in a 27-yr moving window in ERSSTV5 (based on 1854-2019) and HadISST (based on 1870-2019) are 0.16 and 0.15 , respectively. Hence, variability of the spring NTA SSTA-ENSO relation in the observation is similar to that in the 50-member large-ensemble simulations of CanESM2.

To identify which components of internal climate variability impact the spring NTA SSTA-winter ENSO relation, we further compare ten ensemble members with the highest spring NTA SSTA-winter Niño-3.4 correlation coefficients (referred to as HCC members) and 10 ensemble members with the lowest spring NTA SSTA-winter Niño-3.4 correlation coefficients (referred to as LCC members) according to Fig. 5. The ensemble mean of the correlation coefficients for the HCC members is -0.47 . By contrast, the ensemble mean of the correlation coefficients for the LCC members is -0.09 , much less than that for the HCC members. The difference in the correlation coefficient between the HCC and LCC members exceeds the 95\% confidence level according to the Fisher's $r$ to- $z$ transformation (Chen et al. 2015). It should be mentioned that results obtained below remain similar for slight changes of the ensemble members used in the comparative analysis.

Figure 6 compares ensemble means of the SSTA in $\operatorname{MAM}(0)$, $\operatorname{JJA}(0), \operatorname{SON}(0)$, and $\mathrm{D}(0) \mathrm{JF}(1)$ regressed upon the normalized $\operatorname{MAM}(0)$ NTA SST index for the HCC (left column) and LCC members (middle column), as well as their differences (right column). The ensemble means of the associated precipitation and 

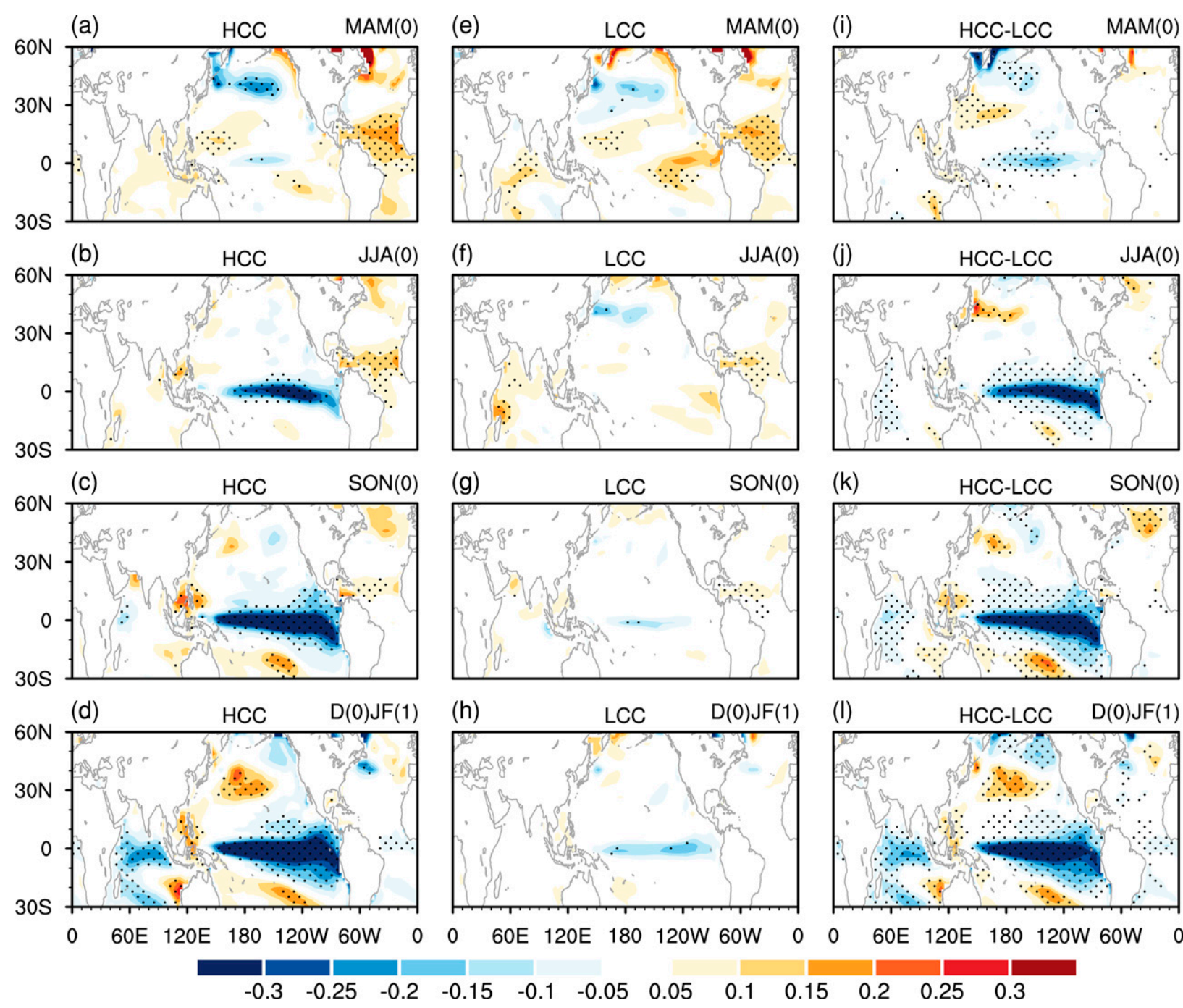

FIG. 6. MMEs of SST ( ${ }^{\circ} \mathrm{C}$ ) anomalies in (a),(e) MAM(0); (b),(f) JJA(0); (c),(g) SON(0); and (d),(h) D(0)JF(1) regressed upon the normalized MAM(0) NTA SST index for the (left) HCC and (center) LCC members, respectively. (right) Differences in the MME of SSTA $\left({ }^{\circ} \mathrm{C}\right)$ between the HCC and LCC members in (i) MAM(0), (j) JJA(0), (k) SON(0), and (l) D(0)JF(1). Stippled regions in (a)-(h) indicate SSTA significant at the $95 \%$ confidence level. Stippled regions in (i)-(l) indicate the differences in the SSTA that are significantly different from zero at the $95 \%$ confidence level.

850-hPa winds anomalies are shown in Fig. 7. Evolutions of SST, precipitation, and low-level wind anomalies for the ensemble mean of HCC members (Figs. 6a-d and 7a-d) bear a resemblance to the corresponding 50 -member means as shown in Fig. 4, but with stronger amplitudes. This suggests that the HCC members can reproduce a significant connection of the spring NTA SSTA with the following winter ENSO. For the LCC members, significant SST warming appears in the NTA in spring and continues to the following autumn (Figs. 6e-g). This feature is similar with that in the ensemble mean of the HCC members (Figs. 6a-c). However, SSTA in the tropical Pacific are extremely weak from $\mathrm{JJA}(0)$ to the following $\mathrm{D}(0) \mathrm{JF}(1)$ (Figs. 6f-h). Correspondingly, easterly wind anomalies and negative precipitation over the tropical Pacific for the ensemble mean of LCC members are much weaker compared to those for the HCC members (Fig. 7). In particular, in MAM(0), tropical western-to-central Pacific is dominated by easterly wind anomalies for the HCC members, which is favorable for the occurrence of a La Niña event in the succedent winter. By contrast, westerly wind anomalies are seen over the tropical Pacific in MAM(0) for the LCC members, which would suppress the occurrence of cold SSTAs in the tropical central-to-eastern Pacific in the subsequent seasons (Ham et al. 2013).

In MAM(0), SSTA differences in the NTA between HCC and LCC members are weak (Fig. 6i). This suggests that the diversity of the spring NTA SSTA-winter ENSO relation between the two groups members is not likely due to the difference in the amplitude of the spring NTA SSTA. On the other hand, differences in the $850-\mathrm{hPa}$ winds over the North 



FIG. 7. As in Fig. 6, but for precipitation (shading, $\mathrm{mm} \mathrm{day}^{-1}$ ) and 850-hPa wind anomalies (vectors, $\mathrm{m} \mathrm{s}^{-1}$ ).

Pacific between the ensemble means of the HCC and LCC members exhibit a negative NPO-like meridional atmospheric pattern, with an anticyclonic anomaly over subtropics and a cyclonic anomaly over midlatitudes (Fig. 7i). Correspondingly, difference in spring SSTA displays a tripolar pattern in the North Pacific (Fig. 6i). Previous studies have demonstrated that boreal winter NPO-related atmospheric anomalies could induce a tripolar SST anomaly pattern in the North Pacific in the succedent spring via modulating surface heat fluxes (Vimont et al. 2001, 2003; Alexander et al. 2010). The SSTA induced by the previous positive (negative) winter NPO can maintain to the following spring and summer, and in turn, force the overlying atmospheric anomalies, including westerly (easterly) wind anomalies over the tropical westernto-central Pacific, and impact the following winter ENSO (Vimont et al. 2001, 2003).

Figures $8 \mathrm{a}-\mathrm{c}$ further show the differences in the MMEs of SLP, $850-\mathrm{hPa}$, and 500-hPa geopotential height anomalies in preceding winter $[\mathrm{D}(-1) \mathrm{JF}(0)]$ regressed upon the $\operatorname{MAM}(0)$
NTA SST index between the HCC and LCC members. A pronounced negative NPO-like atmospheric anomaly pattern is observed over the North Pacific with a quasi-barotropic vertically structure. These results imply that differences in the condition of the preceding winter NPO contribute to the large diversity of the spring NTA SST-subsequent winter ENSO relation among the 50 members of CanEMS2.

It is noted from Fig. 7i that there exist marked negative precipitation anomalies (indicating suppressed convection) in the western equatorial Pacific in $\mathrm{MAM}(0)$ between the $\mathrm{HCC}$ and the LCC. One may ask whether formation of the NPO-like atmospheric anomalies over the North Pacific is due to the spring convective forcing in the western equatorial Pacific. We have examined precipitation anomalies in preceding winter [i.e., $\mathrm{D}(-1) \mathrm{JF}(0)]$. It is found that MMEs of the precipitation anomalies for the HCC and the LCC as well as their differences are weak and statistically insignificant over most parts of the western equatorial Pacific (not shown). Hence, the winter NPO-like atmospheric circulation anomalies (Fig. 8) are leading the 

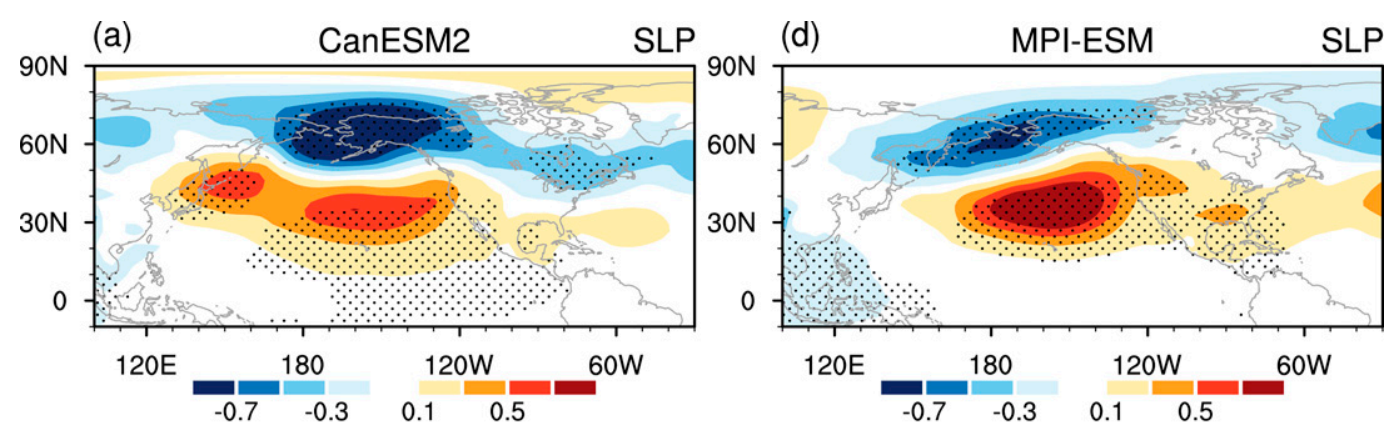

(b)



(c)

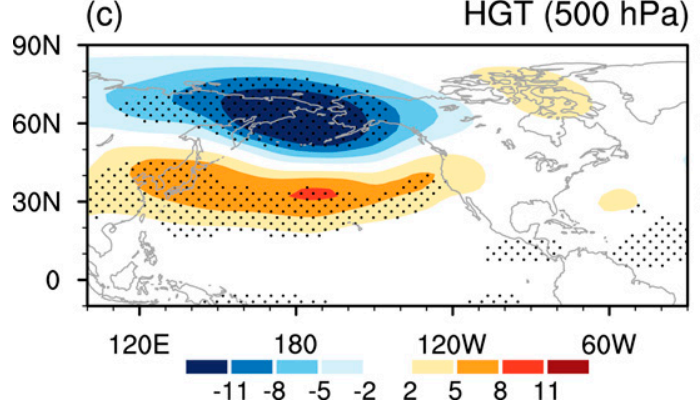

(e)

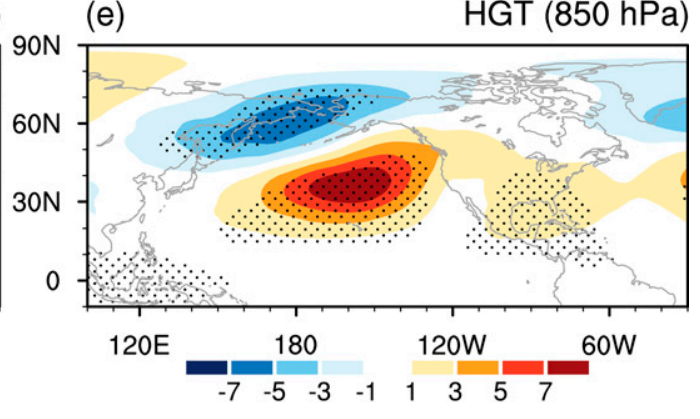

FIG. 8. Differences in the MMEs of (a),(d) SLP (hPa) and (b),(e) 850-hPa; and (c),(f) 500-hPa geopotential height $(\mathrm{m})$ anomalies in preceding winter $[\mathrm{D}(-1) \mathrm{JF}(0)]$ regressed upon the normalized MAM $(0)$ NTA SST index between the HCC and LCC members. Stippled regions indicate the differences that are significantly differently from zero at the $95 \%$ confidence level. The results in (a)-(c) and (d)-(f) are obtained from the CanESM2 and MPI-ESM, respectively.

convective forcing in the western equatorial Pacific that appears in the following spring (Fig. 7i). This implies that formation of the spring convective forcing in the western equatorial Pacific is due to the preceding winter NPO-like atmospheric anomalies. In addition, we have also examined the possible relation of the spring convective forcing in the western equatorial Pacific with the spring NTA SSTA based on observational and reanalysis data. An index is defined to describe the spring convective forcing in the western equatorial Pacific by averaging spring precipitation anomalies over the region of $5^{\circ} \mathrm{S}-5^{\circ} \mathrm{N}, 150^{\circ}-180^{\circ} \mathrm{E}$ (this index is denoted by CFI in the following). Note that results are not sensitive to small variations of the regions used to define the CFI. The results indicate that the spring CFI index has a weak relation with the spring NTA SSTA index over both periods of 1948-79 and 1980-2018. Hence, above evidence confirms that the spring convective forcing in the western equatorial Pacific is not likely able to excite significant spring NTA SSTA and NPO-like atmospheric anomalies.
To confirm the above results obtained from the CanESM2 simulations, we have also examined the 100-member ensemble simulations conducted with MPI-ESM. Large diversity of the correlations is also found in the 100-member MPI-ESM simulations (Fig. 5b). Comparison of Fig. 5a and Fig. 5b indicates that the intermember spread of the spring NTA SSTA-winter ENSO connection is larger in MPI-ESM than that in CanESM2. Standard deviation of the correlation coefficients among the ensemble members is 0.21 for MPI-ESM, versus 0.15 for CanESM2. Larger internal variability in MPI-ESM may be partly due to a larger number of ensemble member in the MPI-ESM (100 members) than that in the CanESM2 (50 members). In addition, this indicates that the internal variability has a stronger modulation on the spring NTA SSTA-ENSO connection in the MPI-ESM compared to that in the CanESM2.

Figures 8d-f show the differences in the MMEs of $\mathrm{D}(-1) \mathrm{JF}(0)$ SLP, 850-hPa, and 500-hPa geopotential height anomalies associated with the spring NTA SST index between 
the 20 highest and lowest correlations MPI-ESM members. An obvious negative NPO-like atmospheric anomaly pattern is apparent over the North Pacific, consistent well with the results obtained from the CanESM2 simulations. Overall, the above analysis suggests that the wintertime NPO tends to be an important internal climate variability in modulating the spring NTA SSTA-following winter ENSO relationship. When preceding winter NPO is in its negative (positive) phase, spring NTA SST warming can (cannot) induce a La Niña-like SST cooling in the following winter.

Based on the above modeling results, we hypothesize that when negative winter NPO is followed by positive spring NTA SSTA, easterly wind anomalies in the tropical westernto-central Pacific in spring-summer generated by the winter NPO will constructively interfere with those induced by the positive spring NTA SSTA. This cooperative effect exerts significant impacts on the following winter La Niña event. However, when positive winter NPO is followed by positive spring NTA SST, the westerly wind anomalies in the tropical western-to-central Pacific induced by the winter NPO will destructively interfere with the easterly wind anomalies generated by the positive spring NTA SSTA. Because of this cancellation, spring positive NTA SSTA is followed by weak easterly wind anomalies over the tropical-to-western Pacific. Hence, spring NTA SSTA has a weak impact on the following winter La Niña event. This hypothesis will be further confirmed in the next section using the observational data.

\section{Modulation of the spring NTA SST-subsequent winter ENSO relation by preceding winter NPO in the observations}

Previous studies have demonstrated that wintertime NPOrelated atmospheric circulation anomalies could exert strong influences on the occurrence of following winter ENSO events via the so-called seasonal footprinting mechanism (SFM) (Vimont et al. 2001, 2003; Alexander et al. 2010). In this section, we further examine the influence of the winter NPO on the spring NTA SST-following winter NPO connection based on the observational data over the period of 1948-2018.

Figure 9 shows seasonal evolutions of SST, 850-hPa winds, and precipitation anomalies from $\mathrm{D}(-1) \mathrm{JF}(0)$ to $\mathrm{D}(0) \mathrm{JF}(1)$ regressed upon the $\mathrm{D}(-1) \mathrm{JF}(0)$ NPO index in the observations. Here, the NPO index is defined as the difference in the normalized SLP anomalies between regions of $55^{\circ}-72.5^{\circ} \mathrm{N}$, $180^{\circ}-140^{\circ} \mathrm{W}$ and $15^{\circ}-27.5^{\circ} \mathrm{N}, 175^{\circ} \mathrm{E}-147.5^{\circ} \mathrm{W}$, following Furtado et al. (2012). According to Fig. 9, the SFM can be briefly described as follows. During a positive phase of the winter NPO, a cyclonic anomaly appears in the subtropics and an anticyclonic anomaly occurs in the midlatitude North Pacific (Fig. 9a). The associated southwesterly wind anomalies oppose the climatological trade winds (Fig. 9a) and lead to SST warming in the subtropical North Pacific (Fig. 9b) via reducing the total surface wind speed and upward surface latent heat flux (not shown). SST warming in the subtropical North Pacific generated by the preceding positive NPO maintains to the following spring and summer (Figs. 9a,c) via the wind-evaporation-SST feedback (Xie and Philander 1994; Vimont et al. 2001, 2003), and leads to increase in the atmospheric heating there (indicated by significant positive precipitation anomalies) (Figs. 9b-d). Increase in the atmospheric heating over the subtropical North Pacific in spring and summer would induce strong westerly wind anomalies over the tropical western-to-central Pacific via Rossby wave type atmospheric responses (Figs. 9c,d). Subsequently, the westerly wind anomalies over the tropical western-to-central Pacific bring positive SSTAs in the tropical central-to-eastern Pacific via triggering eastward propagating warm equatorial Kelvin waves (Figs. 9c-g). Finally, an El Niño-like SST anomaly pattern is generated in the following winter via a Bjerknes-like positive air-sea interaction (Bjerknes 1969) (Figs. 9e-j). Via the above processes, a positive winter NPO has an impact on the following winter El Niño (Vimont et al. 2001, 2003). The physical processes for the impact of negative winter NPO on the following winter La Niña are similar but with opposite signals (Vimont et al. 2001, 2003).

It is noted that the correlation between the winter NPO index and its following spring NTA SST index is very weak in the observation, with a correlation coefficient of only 0.02 for the period of 1948-2018. From Fig. 9c, it is also clear that SSTAs in the NTA are weak in association with the winter NPO index. These results suggest that the winter NPO index tends to be independent of the spring NTA SST index. To examine the modulation of the winter NPO on the relationship between spring NTA SSTA and its following winter ENSO, Fig. 10 displays scatterplots of the spring NTA SST index versus succedent winter Niño-3.4 SST index when the spring NTA SST index and the preceding winter NPO index have the same and opposite signs. The correlation coefficient between the spring NTA SST index and the subsequent winter Niño-3.4 SST index is only -0.06 when the spring NTA SST index has the same sign as the preceding winter NPO index (Fig. 10a). By contrast, the spring NTA SST index has a significant correlation of -0.51 (Fig. 10b), significant at the $99 \%$ confidence level, with the following winter Niño-3.4 SST index when the spring NTA SST and preceding winter NPO indices have the opposite sign. The difference in the correlation coefficient between the two $(0.06$ and -0.51$)$ also exceeds the $95 \%$ confidence level according to the Fisher's $r$-to- $z$ transformation (Chen et al. 2015). Above results can also be obtained in the large-ensemble simulations of CanESM2 and MPI-ESM (Figs. 10c-f). In particular, when the spring NTA SST and preceding winter NPO indices have the same sign, the correlation coefficients between the spring NTA SST index and following winter Niño-3.4 SST index are very weak in the CanESM2 (0.01) and MPI-ESM $(r=-0.05)$ (Figs. 10c,e). However, spring NTA SSTA has a significant negative relation with the following winter Niño-3.4 SST index when the spring NTA SST and preceding winter NPO indices have the opposite sign (Figs. 10d,f). It should be mentioned that significant modulation of the winter NPO on the spring NTA SSTA-ENSO relationship could also be found before and after the late 1970s (not shown). In this study, we extend the analysis period to 1948-2018 because the results 


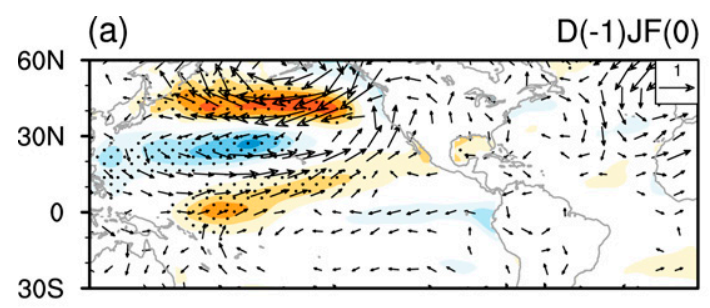

(b)
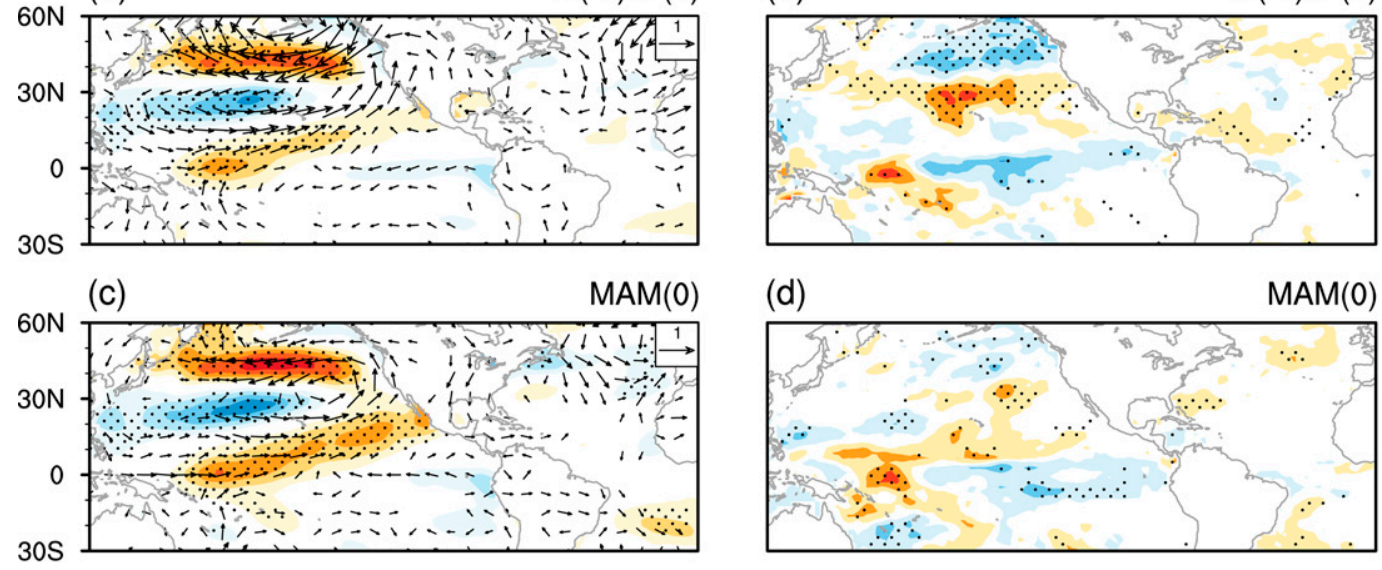

(d)
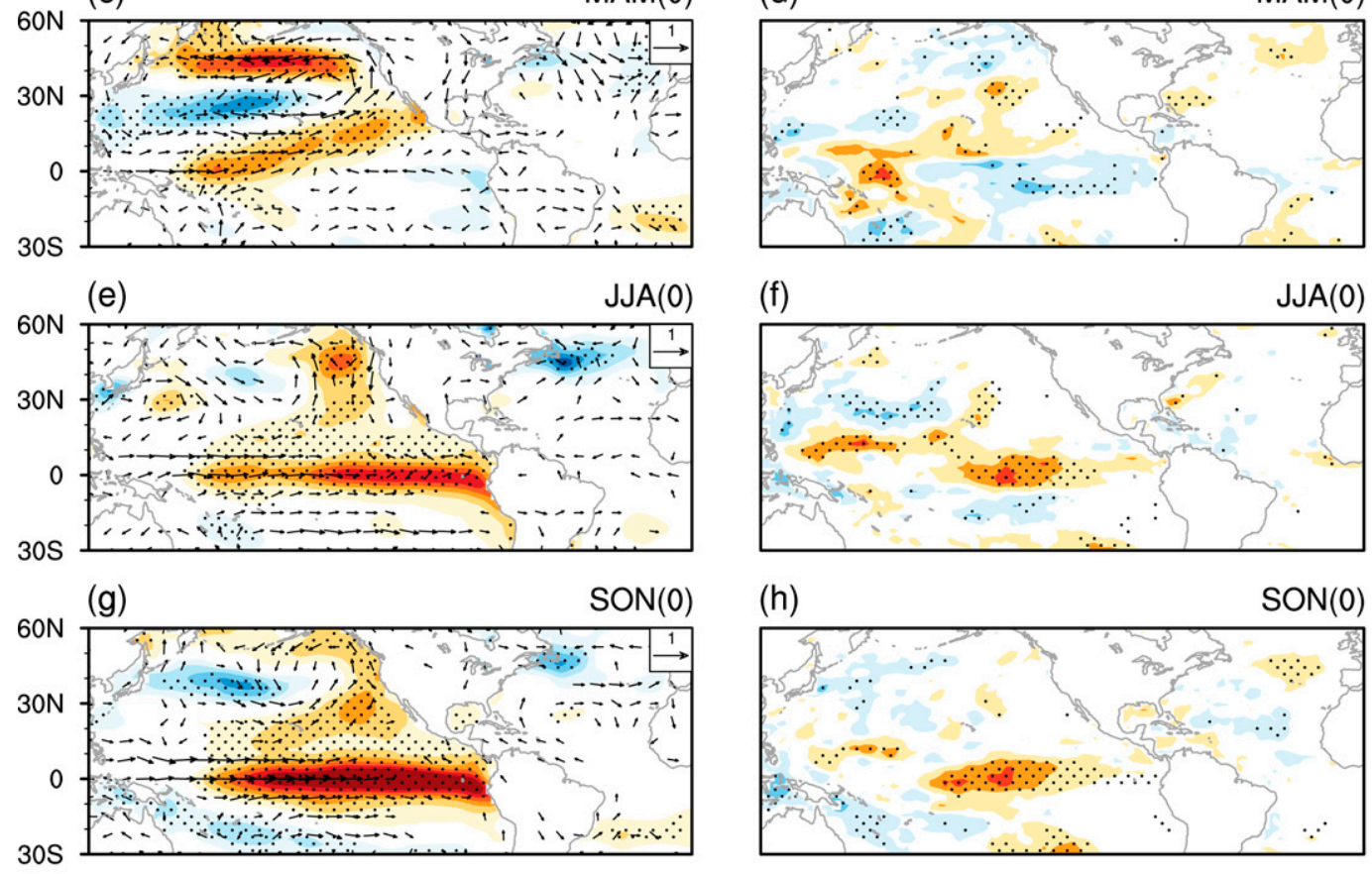

(h)
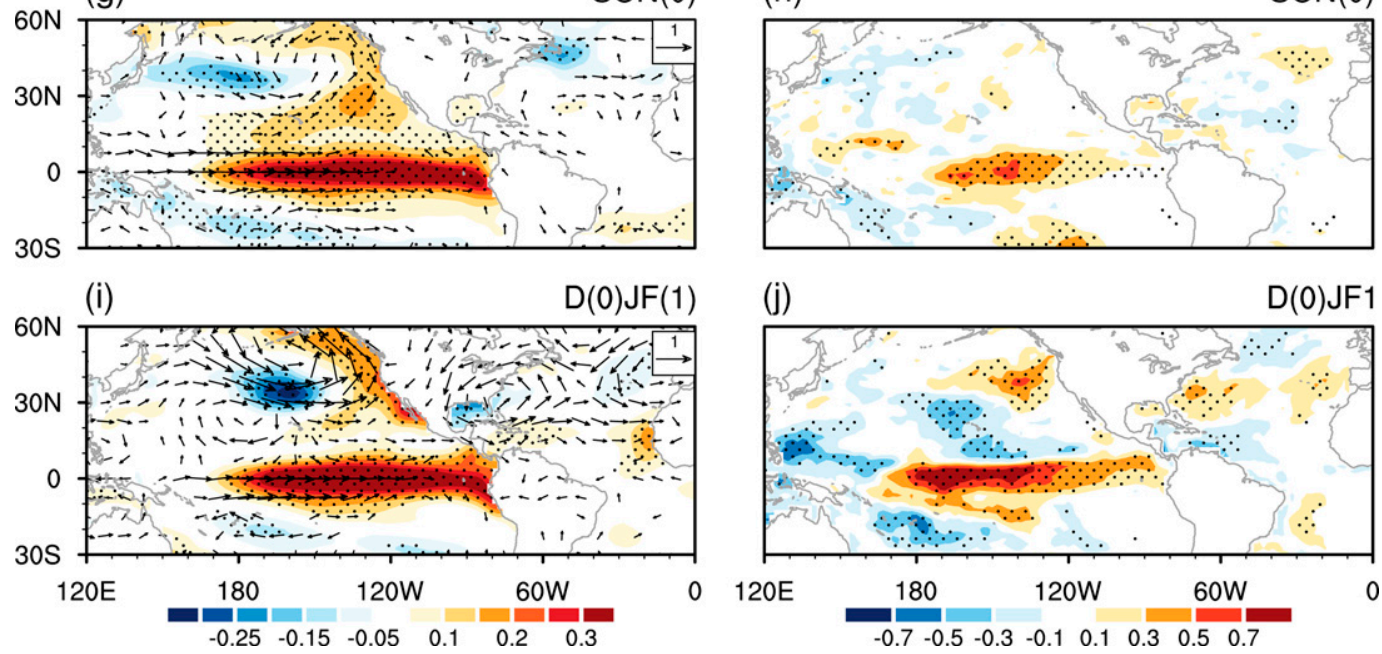

FIG. 9. Anomalies of (left) SST (shading) and $850-\mathrm{hPa}$ winds (vectors) and (right) precipitation in (a),(b) $\mathrm{D}(-1) \mathrm{JF}(0)$; (c),(d) MAM(0); (e),(f) JJA(0); (g),(h) SON(0); and (i),(j) D(0)JF(1) regressed upon the normalized $\mathrm{D}(-1) \mathrm{JF}(0)$ NPO index over 1950-2018 in the observations. Stippled regions indicate SST and precipitation anomalies significant at the $95 \%$ confidence level. Units of SST, precipitation, and winds are ${ }^{\circ} \mathrm{C}, \mathrm{mm} \mathrm{day}^{-1}$, and $\mathrm{m} \mathrm{s}^{-1}$, respectively.

may appear to be more robust and credible when they are obtained based on the observational data over a longer time period.

Figure 11 further compares seasonal evolutions of SSTA from $\operatorname{MAM}(0)$ to $\mathrm{D}(0) \mathrm{JF}(1)$ in association with the $\operatorname{MAM}(0)$ NTA SST index when the winter NPO and spring NTA SST indices have the same (left column) and opposite (right column) signs. Figure 12 presents the corresponding $850-\mathrm{hPa}$ wind and precipitation anomalies. Spatial patterns of SSTAs in the North Atlantic in $\operatorname{MAM}(0)$ are similar for the opposite and same sign years, both of which show a tripolar SST anomaly pattern with significant positive anomalies in the NTA and midlatitudes, and negative anomalies in the subtropical northwestern Atlantic (Figs. 11a,b). However, spatial patterns of the spring SSTA in the North Pacific show remarkable differences between the opposite and same sign years. For the opposite sign years (e.g., negative winter NPO followed by positive spring NTA SSTA), a negative phase of winter NPO 
(a)



(c) same phase(CanESM2)



(e) same phase(MPI-ESM)

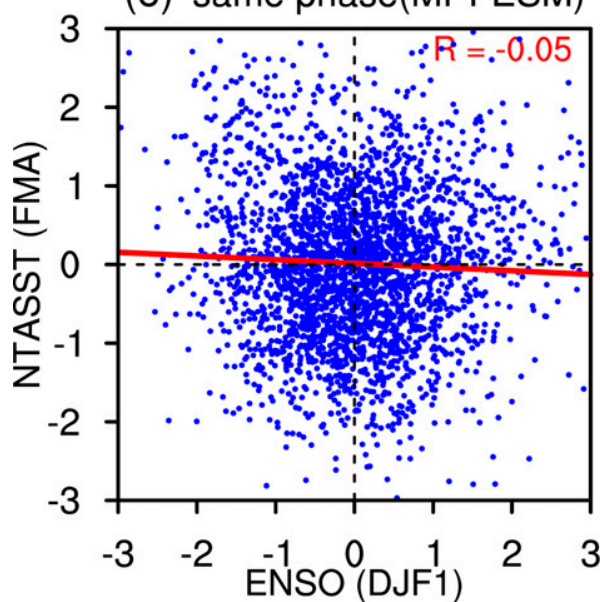

(b)



(d) oppo phase(CanESM2)

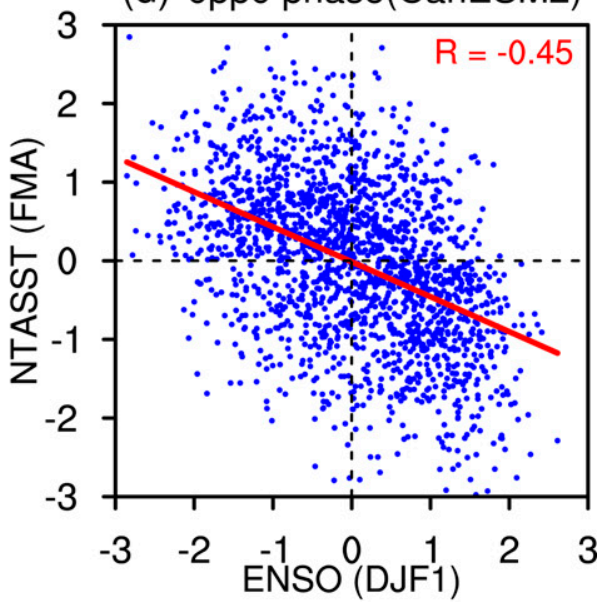

(f) oppo phase(MPI-ESM)

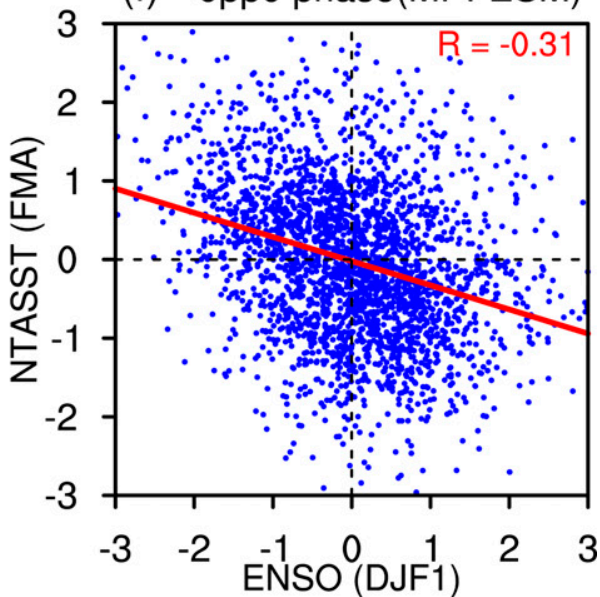

FIG. 10. Scatterplots of the MAM(0) NTA SST index vs D(0)JF(1) Niño-3.4 SST index when the $\mathrm{D}(-1) \mathrm{JF}(0) \mathrm{NPO}$ and the MAM(0) NTA SST indices have the (left) same sign and (right) opposite sign in the (a),(b) observations, (c),(d) 50-member simulations of the CanESM2, and (e),(f) 100-member simulations of the MPI-ESM. 

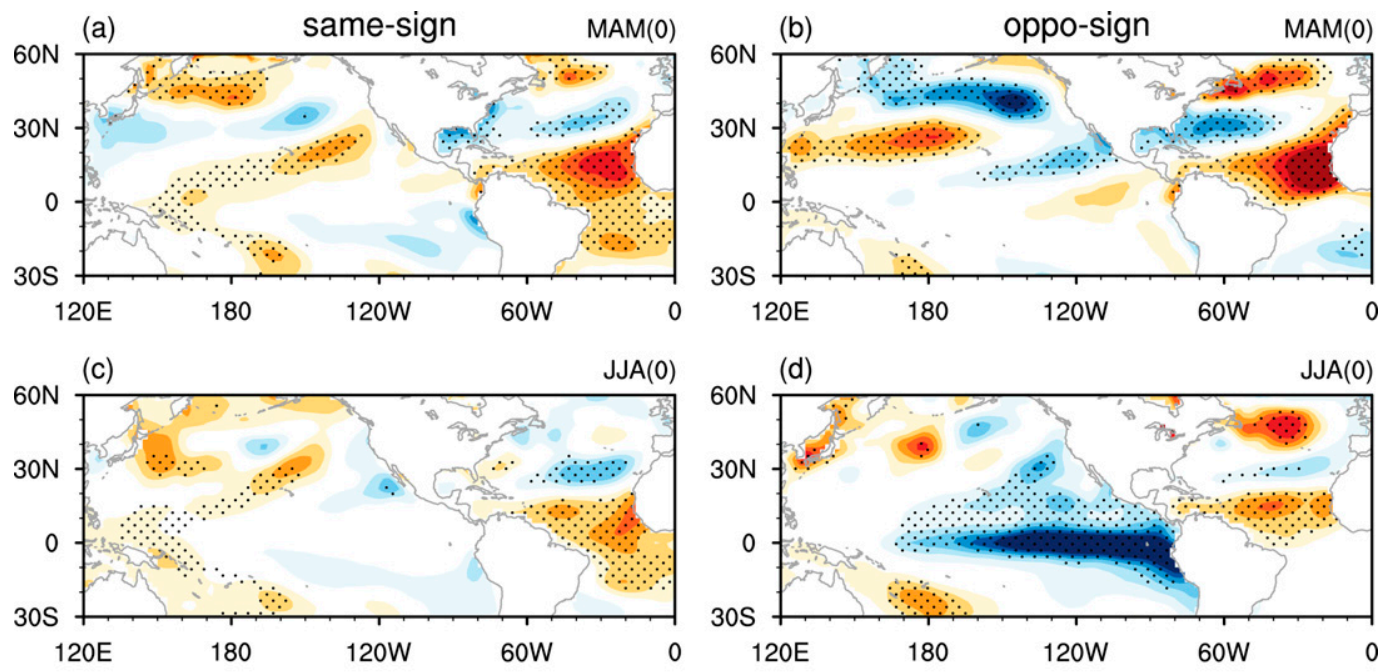

(e)
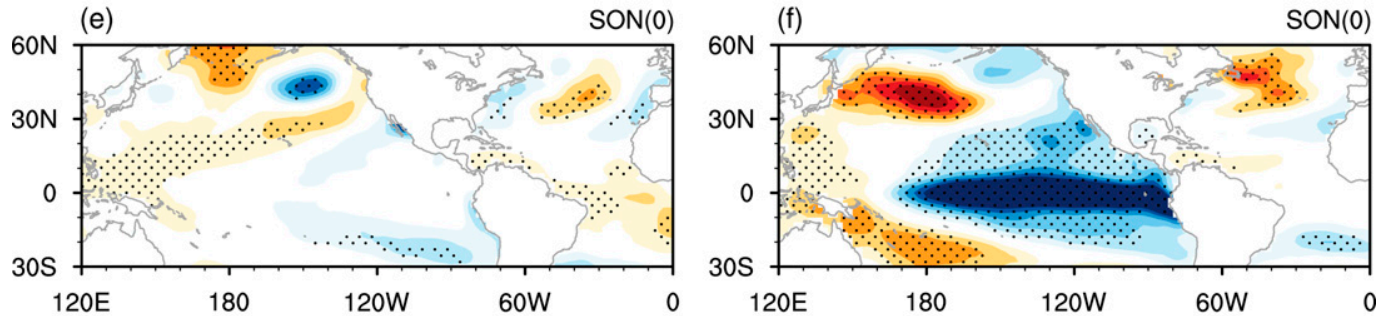

(g)

$\mathrm{D}(0) \mathrm{JF}(1)$
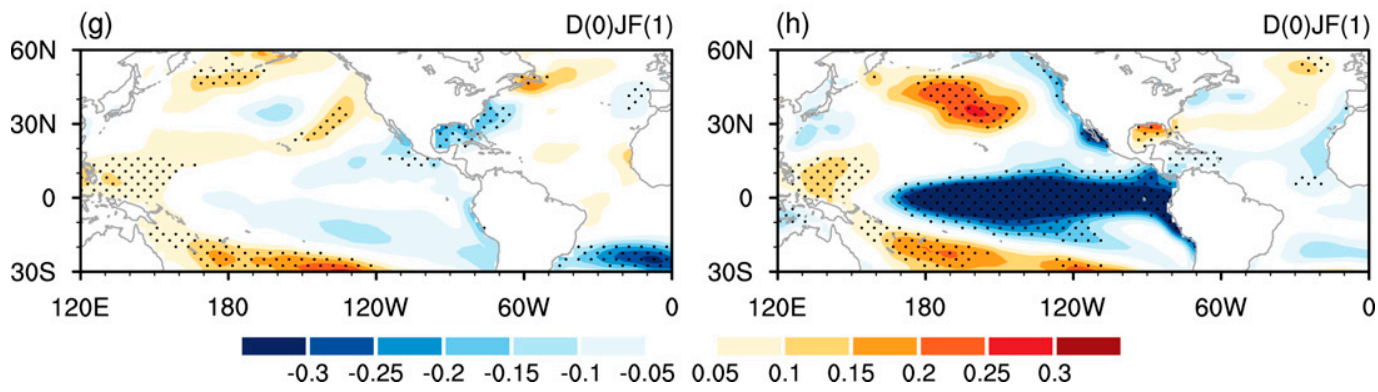

FIG. 11. Anomalies of SST $\left({ }^{\circ} \mathrm{C}\right)$ in (a),(b) $\mathrm{MAM}(0)$; (c),(d) JJA(0); (e),(f) SON(0); and (g),(h) D(0)JF(1) regressed against the normalized MAM $(0)$ NTA SST index when the $\mathrm{D}(-1) \operatorname{JF}(0)$ NPO and MAM $(0)$ NTA SST indices have the (left) same sign and (right) opposite sign over 1948-2018. Stippled regions indicate SSTA significant at the 95\% confidence level.

would induce a tripolar SSTA pattern in the North Pacific in the following spring via modulating surface heat flux (not shown), especially with significant negative SSTAs over the subtropical central-to-eastern North Pacific (Fig. 11b). This SSTA pattern in the North Pacific bears a resemblance to that associated with the negative phase of the North Pacific meridional mode (Chiang and Vimont 2004; Chang et al. 2007), which would induce easterly wind anomalies over the tropical western-to-central Pacific and favor the occurrence of $\mathrm{La}$ Niña events in the following winter as indicated by previous studies (Chang et al. 2007; Alexander et al. 2010; Larson and Kirtman 2013). Hence, the negative winter NPO-generated spring easterly wind anomalies play a constructive role in the easterly wind anomalies over the tropical western-to-central Pacific induced by the spring NTA SST warming. This cooperative effect would lead to strong easterly wind anomalies over the tropical western-to-central Pacific (Figs. 12b,d) and contribute to large negative SSTAs in the tropical central-to-eastern Pacific during the following winter via triggering eastward propagating warm Kelvin waves and positive air-sea interaction processes (Figs. 11d,f,h, and 12d,f,h).

By contrast, for the same sign years (e.g., positive winter NPO followed by positive spring NTA SSTA), a tripolar SSTA pattern is also seen in the North Pacific in spring (Fig. 11a), but with reverse anomalies compared to those in the opposite sign years. In particular, significant SST warmings appear in the tropical central-to-eastern North Pacific, similar to the positive phase of the North Pacific meridional mode (Chiang and Vimont 2004; Chang et al. 2007). Hence, the SST warming in the tropical North Pacific induced by 



FIG. 12. As in Fig. 11, but for precipitation $\left(\mathrm{mm} \mathrm{day}^{-1}\right)$ and $850-\mathrm{hPa}$ winds $\left(\mathrm{m} \mathrm{s}^{-1}\right)$ anomalies.

preceding positive NPO would lead to westerly wind anomalies in the tropical western-to-central Pacific (Chang et al. 2007; Alexander et al. 2010), which play a destructive role in the easterly wind anomalies over the tropical western-to-central Pacific induced by the spring NTA SST warming. This counter effect results in weak easterly wind anomalies over the tropical western-to-central Pacific in spring and summer (Figs. 12c,e). As a result, no significant SSTAs could be induced in the tropical central-to-eastern Pacific (Figs. 11c,e). Overall, for the same sign years, there is weak air-sea feedback to SSTAs in the tropical central-to-eastern Pacific and therefore no La Niña-like SSTA anomaly pattern occurs in the following winter (Fig. 11g).

The above comparison indicates that winter NPO has a notable modulation on the following spring NTA SST-ENSO relation. The implication of this result is that the predictability of winter ENSO based on spring NTA SSTA may also be influenced by the preceding winter NPO. To confirm this, two empirical models are constructed to predict the winter Niño3.4 SST index according to the preceding spring NTA SST index for the same-sign and opposite-sign scenarios, respectively (Duan et al. 2013; Song et al. 2016b). Equations associated with the two empirical models are written as follows:

$$
\begin{gathered}
\text { Niño34 }\left.4_{\text {predict }}\right|_{\text {same-sign }}=a_{1} \times \text { NTASST }+b_{1}, \\
\text { Niño34 } \\
\text { predict }\left.\right|_{\text {opposite-sign }}=a_{2} \times \mathrm{NTASST}+b_{2},
\end{gathered}
$$

where Niño34 $4_{\text {predict }}$ indicates the winter Niño-3.4 index calculated by the empirical model. As listed in Table 1, there are 35 years for both the same-sign and opposite-sign scenarios. The first 29 years in both same-sign and opposite-sign scenarios are considered as training cases and are employed to estimate the regression coefficients in Eqs. (1) and (2), whereas the remaining 6 years are considered as independent testing 
(a)


FIG. 13. D(0)JF(1) Niño-3.4 SST index in the observation (red line), and the hindcast and forecast (blue line) of the $\mathrm{D}(0) \mathrm{JF}(1) \mathrm{Niño-}$ 3.4 SST index by an empirical model using the MAM(0) NTA SST index for the years when the $\mathrm{D}(-1) \mathrm{JF}(0) \mathrm{NPO}$ and MAM(0) NTA SST indices have the (a) same sign and (b) opposite sign. The vertical green line separates the hindcast (i.e., training) and forecast (i.e., testing) periods. The correlation coefficients between the $\mathrm{D}(0) \mathrm{JF}(1)$ Niño-3.4 SST index in the observation and that obtained from the empirical model during the hindcast and forecast periods are shown at the bottom center of the panels.

cases, since data from those 6 years are not employed to estimate the empirical model coefficients.

The performance levels of the empirical models for the opposite-sign and same-sign scenarios are shown in Figs. 13a and 13b, respectively. Red lines in Fig. 13 denote the observed winter Niño-3.4 index, while blue lines represent the modelestimated winter Niño-3.4 index. For the opposite-sign scenario (Fig. 13b), the model can well reproduce the observed winter Niño-3.4 SST index during the training period, with a correlation coefficient of 0.42 that is significant at the $95 \%$ confidence level. Although there are only 6 years in the independent testing period, Fig. 13b suggests that the empirical model has a good performance in predicting the winter Niño3.4 SST index. In particular, the extreme large values of the observed Niño-3.4 SST index can be accurately predicted (Fig. 13b). The correlation coefficient between the observed and model-estimated Niño-3.4 index reaches 0.83 , which is also statistically significant at the $95 \%$ confidence level. By contrast, in the same-sign scenario (Fig. 13a), performance of the empirical model is poor. The correlation coefficient between the observed and model-estimated winter Niño-3.4 SST index is only 0.11 in the training period, and is even negative $(r=-0.69)$ in the independent testing period. This indicates that it would lead to false alarms if using the spring NTA SSTA to predict the following winter ENSO events during the opposite-sign scenarios. Results from the empirical models confirm the important modulation of the preceding winter NPO on the following spring NTA SST-ENSO relation.

Considering that winter NPO and spring NTA SSTAs are independent, while they exert a joint effect on the following winter ENSO, we have further established an empirical prediction model of the winter ENSO using both preceding winter NPO and spring NTA SSTA as predictors, which is written as follows:

$$
\mathrm{Niño}_{\text {predict }}=a \times \mathrm{NTASST}_{\text {spring }}+b \times \mathrm{NPO}_{\text {winter }}
$$

The skill of this empirical prediction model is cross validated via a leave-one-out scheme (discarding one year from the analysis period, then calculating the regression coefficient based on the remaining years, and finally hindcasting the value for the discarded year; Ham et al. 2013). From Fig. 14, it shows that if both the winter NPO index and spring NTA SSTA index are used to hindcast the following winter Niño34 index, the cross-validated correlation is 0.5 , which is higher than that using only the winter NPO $(R=0.33)$ or spring NTA SSTA $(R=0.3)$ to predict the following winter Niño34 index. This again confirms that winter NPO has a strong modulation on the predictability of winter ENSO based on the condition of spring NTA SSTA.

\section{Summary and discussion}

This study examines the linkage between the spring NTA SSTA and the following winter ENSO in the large-ensemble simulations of CanESM2 and MPI-ESM, and compares them with the result in observations. MME of CanEMS2 and MPIESM can reproduce the out-of-phase relation of the spring NTA SSTA with the succedent winter ENSO. However, there exists a large diversity of the spring NTA SSTA-winter ENSO connection among different ensemble members due to the internal climate variability. A comparison of the members with high and low spring NTA SSTA-winter ENSO correlations suggests that the preceding winter NPO is an important

TABLE 1 List of the years when $\mathrm{D}(-1) \mathrm{JF}(0)$ NPO and MAM(0) NTA SST indices have the same sign and opposite sign.

\begin{tabular}{cc}
\hline \hline Same sign & Opposite sign \\
\hline $1949,1950,1951,1952,1956,1961,1962,1963,1964,1966,1967$, & $1953,1954,1955,1957,1958,1959,1960,1965,1968,1970,1972$, \\
$1969,1971,1975,1976,1977,1978,1980,1983,1984,1985,1986$, & $1973,1974,1979,1981,1982,1987,1988,1990,1991,1993,1994$, \\
$1989,1992,1996,1999,2001,2002,2004,2005,2010,2011,2012$, & $1995,1997,1998,2000,2003,2006,2007,2008,2009,2013,2014$, \\
2016,2017 (35 years) & 2015,2018 (35 years) \\
\hline
\end{tabular}




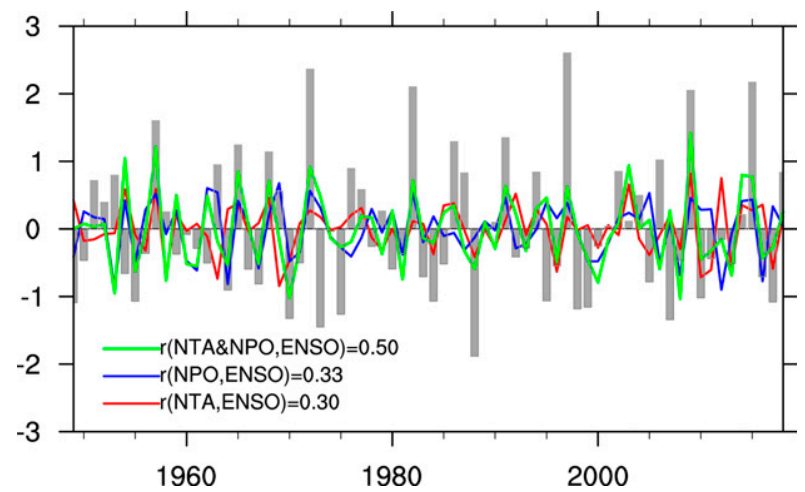

FIG. 14. Normalized time series of the $\mathrm{D}(0) \mathrm{JF}(1)$ Niño-3.4 index (bars) during 1949-2018. The cross-validated hindcasts of the $\mathrm{D}(0) \mathrm{JF}(1)$ Niño-3.4 index by empirical models using the $\mathrm{D}(-1) \mathrm{JF}$ (0) NPO index alone (blue line), using the FMA(0) NTA SST index alone (red line), and using both the D(-1)JF (0) NPO index and the FMA(0) NTA SST index (green line).

source of the internal climate variability mode in modulating the connection. The remarkable modulation of the winter NPO on the spring NTA SSTA-winter ENSO relationship can also be found based on the observational data. When preceding winter NPO and spring NTA SST indices have the opposite (same) sign, spring NTA SST index tends to have a significant (weak) correlation with the following winter Niño3.4 SST index. Specifically, spring SST warming in the NTA can (cannot) lead to a significant La Niña-like SST cooling in the tropical central-to-eastern Pacific during the subsequent winter if preceding winter NPO is in its negative (positive) phase.

The physical process for the modulation of the winter NPO on the following spring NTA SSTA-winter ENSO relation is schematically summarized in Fig. 15. Spring SST warming in the NTA maintains to the following summer and leads to enhanced atmospheric heating there, which could induce an anomalous walker circulation with upward motion over the tropical Atlantic and downward motion over the tropical central Pacific. The downward motion anomalies over the tropical central Pacific are accompanied by easterly wind anomalies over the tropical western-to-central Pacific, which plays an important role in relaying impact of the spring NTA SST warming on the following winter La Niña-like cooling in the tropical central-to-eastern Pacific. When preceding winter NPO is in its negative phase, an anticyclonic anomaly appears in the subtropics and a cyclonic anomaly occurs over the midlatitude North Pacific. The anomalous northeasterly winds to the east side of the anomalous anticyclone over the subtropical North Pacific lead to SST cooling there via increase in the total wind speed and surface evaporation. The subtropical SST cooling, in turn, contributes to the maintenance and southwestward movement of the anomalous anticyclone, which leads to strong easterly wind anomalies over the tropical western-to-central Pacific. Hence, the negative winter NPO-generated easterly wind anomalies over the tropical western-to-central Pacific bring a constructive influence on


FIG. 15. Schematic diagrams showing the physical processes for the modulation of the winter NPO on the relationship between spring NTA SST and succedent winter ENSO. Red and blue shading indicates warm and cold SSTA, respectively. "C" and "AC" indicate anomalous cyclone and anticyclone, respectively. Green arrows indicate tropical atmospheric anomalies generated by spring NTA SSTA. Pink arrows represent the winter NPO-related atmospheric anomalies.

the easterly wind anomalies induced by the spring NTA SST warming. This cooperative effect enhances the easterly wind anomalies over the tropical western-to-central Pacific and leads to pronounced negative SSTA in the tropical easterncentral Pacific (Fig. 15a). The reverse is true for the years when positive winter NPO is followed by spring NTA SST cooling. Hence, the linkage between the spring NTA SST with the following winter ENSO tends to be strong when preceding winter NPO and spring NTA SST indices have the opposite signs (Fig. 15a).

By contrast, if winter NPO and spring NTA SST indices have the same signs (Fig. 15b), for example, positive winter NPO phase is followed by spring NTA SST warming, the easterly wind anomalies generated by the spring NTA SST warming would be offset by the westerly wind anomalies over the tropical western-to-central Pacific induced by preceding positive winter NPO. This counter effect leads to weak easterly wind anomalies over the tropical western-to-central Pacific in spring and summer and cannot result in clear SST cooling the tropical central-to-eastern Pacific in the following winter. The winter NPO is also found to play an important modulation influence on the predictability of winter ENSO in association with the spring NTA SST. Information of the preceding winter NPO should be considered when predicting winter ENSO events according to the spring NTA SST. 
Although this study focuses on examining impact of the winter NPO on the spring NTA SSTA-ENSO relationship, the same logic could be applied to the NTA SSTA impacts on the winter NPO-ENSO relationship given the compounding effects of the winter NPO and spring NTA SSTA on the following winter ENSO. Figure S5 displays scatterplots of the winter $[\mathrm{D}(-1) \mathrm{JF}(0)] \mathrm{NPO}$ index versus subsequent winter [D(0)JF(1)] Niño-3.4 SST index when the spring [MAM(0)] NTA SST index and the $\mathrm{D}(-1) \mathrm{JF}(0)$ NPO index have the same and opposite signs. The results indicate that the correlation coefficients between the winter NPO index and the subsequent winter Niño-3.4 SST index are 0.25 and 0.49 when the spring NTA SST index and the preceding winter NPO index have the same and opposite signs, respectively ( Fig. S5). This suggests that the winter NPO also has a closer connection with the following winter ENSO when the spring NTA SST index and the preceding winter NPO index have the opposite sign. However, the difference in the correlation coefficients between the two (i.e., 0.25 and 0.49 ) cannot pass the $90 \%$ confidence level according to the Fisher's $r$-to- $z$ transformation. Hence, modulation of the winter NPO on the spring NTA SSTA-ENSO relation tends to be stronger compared to the modulation of the spring NTA SSTA on the winter NPO-ENSO relation. The relative contributions of the winter NPO (extratropical forcing) and spring NTA SSTA (tropical forcing) on the occurrence of following winter ENSO would be comprehensively investigated in the future via running a set of fully coupled climate model experiments through constraining the winter NPO or the spring NTA SSTA.

Previous studies indicated that SSTAs in the Indian Ocean are related to the Indian Ocean dipole (IOD) and Indian Ocean basin mode (IOBM) (Izumo et al. 2010, 2016), SSTAs in the southern Pacific are related to the Southern Pacific Meridional Mode (SPMM) (Min et al. 2017), and the Atlantic Niño (Rodríguez-Fonseca et al. 2009; Ding et al. 2012) also influences the winter ENSO. From Fig. 6i, differences in the spring SST anomalies related to the spring NTA SST index in the southern Pacific and equatorial Atlantic between the HCC and LCC members are weak. This indicates that the SPMM and Atlantic Niño are not the main sources of internal variability in impacting connection of the spring NTA SSTA with the following winter ENSO. A negative IOD-like pattern appears in the Indian Ocean, with positive SSTAs in the eastern Indian Ocean and negative SSTAs of much weaker amplitude in the western Indian Ocean. This implies that IOD variability may also contribute to the source of the internal variability in affecting the spring NTA SSTA-ENSO relation. However, SSTAs in the Indian Ocean are less prominent compared to those in the North Pacific, indicating North Pacific SST anomalies contribute more to the source of internal variability. The role of the Indian Ocean SST variability in the change of the spring NTA SSTA-ENSO relation should be further examined in the future. In addition, a recent study indicated that a wintertime North American dipole (NAD) pattern, which is referred to as a meridional oscillation pattern in SLP anomalies over northeastern North America and western tropical North Atlantic, in boreal winter has an impact on the central Pacific type of El Niño event during the following winter (Ding et al. 2017b). Differences in the winter
SLP anomalies between the HCC and LCC members also reveal a dipole pattern between northeastern North America and western tropical North Atlantic (Fig. 8), but with much weaker amplitude and less significant compared to those in the North Pacific. In addition, differences in SLP anomalies over North Atlantic and North America are not consistent between the two models (Fig. 8). Hence, compared to NPO, NAD contributes less to the internal climate variability in modulating the spring NTA SSTA-ENSO relation.

Previous studies indicated that changes in the mean state of climate over the tropical Pacific and Atlantic could also impact interbasin interactions (Cai et al. 2019). We have examined differences in the spring climatology of SST, precipitation, and SLP between the HCC and LCC members, and found the climatological differences are weak over most parts of Pacific and Atlantic (not shown). This implies that variations of the mean state are not the main source of internal climate variability that contributes to changes of the spring NTA SSTA-ENSO relation.

This study uses large-ensemble simulations generated by two different coupled climate models to investigate interbasin interactions in the tropics and the role of internal climate variability in modulating the connections. One may also use pacemaker simulations by prescribing SSTAs in the NTA in a fully coupled climate model to explore the connection of NTA SSTAs with ENSO or responses of remote climate anomalies to NTA SSTAs (e.g., Deser et al. 2017). In addition, large-ensemble pacemaker simulations may also be employed to explore the role of internal climate variability in modulating the interbasin interactions.

Acknowledgments. We thank the Editor, Dr. Agus Santoso, and four anonymous reviewers for their constructive suggestions, which helped to improve the paper. This work was supported jointly by the National Natural Science Foundation of China (Grants 41721004, 42175039, and 41961144025), and the Chinese Academy of Sciences Key Research Program of Frontier Sciences (QYZDY-SSWDQC024). The authors declare that they have no conflict of interest.

Data availability statement. The NCEP-NCAR reanalysis data were obtained from https://psl.noaa.gov/data/reanalysis/ reanalysis.shtml, the ERSSTV5 SST data were derived from https://psl.noaa.gov/data/gridded/data.noaa.ersst.v5.html, the HadISST SST data were derived from https://www.metoffice. gov.uk/hadobs/hadisst/, the CanESM2 large-ensemble simulation data were derived from https://open.canada.ca/data/en/ dataset/, and the MPI-ESM large-ensemble simulation data were obtained from https://esgf-data.dkrz.de/search/mpi-ge/.

\section{REFERENCES}

Alexander, M. A., I. Bladé, M. Newman, J. R. Lanzante, N.-C. Lau, and J. D. Scott, 2002: The atmospheric bridge: The influence of ENSO teleconnections on air-sea interaction over the global oceans. J. Climate, 15, 2205-2231, https://doi.org/ 10.1175/1520-0442(2002)015<2205:TABTIO>2.0.CO;2. 
— D. J. Vimont, P. Chang, and J. D. Scott, 2010: The impact of extratropical atmospheric variability on ENSO: Testing the seasonal footprinting mechanism using coupled model experiments. J. Climate, 23, 2885-2901, https://doi.org/10. 1175/2010JCLI3205.1.

Anderson, B. T., 2003: Tropical Pacific sea-surface temperatures and preceding sea level pressure anomalies in the subtropical North Pacific. J. Geophys. Res., 108, 4732, https://doi.org/10. 1029/2003JD003805.

— , and R. C. Perez, 2015: ENSO and non-ENSO induced charging and discharging. Climate Dyn., 45, 2309-2327, https://doi.org/10.1007/s00382-015-2472-x.

Arora, V. K., and Coauthors, 2011: Carbon emission limits required to satisfy future representative concentration pathways of greenhouse gases. Geophys. Res. Lett., 38, L05805, https://doi.org/10.1029/2010GL046270.

Battisti, D. S., and A. C. Hirst, 1989: Interannual variability in a tropical atmosphere-ocean model: Influence of the basic state, ocean geometry and nonlinearity. J. Atmos. Sci., 46, 1687-1712, https://doi.org/10.1175/1520-0469(1989)046<1687: IVIATA $>2.0 . \mathrm{CO} ; 2$.

Bjerknes, J., 1969: Atmospheric teleconnections from the equatorial Pacific. Mon. Wea. Rev., 97, 163-172, https://doi.org/10. 1175/1520-0493(1969)097<0163:ATFTEP>2.3.CO;2.

Bretherton, C. S., M. Widmann, V. P. Dymnikov, J. M. Wallace, and I. Blade, 1999: The effective number of spatial degrees of freedom of a time-varying field. J. Climate, 12, 1990-2009, https://doi.org/10.1175/1520-0442(1999)012\%3C1990: TENOSD\%3E2.0.CO;2.

Cai, W. J., and Coauthors, 2019: Pan-tropical climate interactions. Science, 363, eaav4236, https://doi.org/10.1126/science.aav4236.

Chan, J. C. L., 2005: Interannual and interdecadal variations of tropical cyclone activity over the western North Pacific. Meteor. Atmos. Phys., 89, 143-152, https://doi.org/10.1007/ s00703-005-0126-y.

Chang, P., L. Zhang, R. Saravanan, D. J. Vimont, J. C. H. Chiang, L. Ji, H. Seidel, and M. K. Tippett, 2007: Pacific meridional mode and El Niño-Southern Oscillation. Geophys. Res. Lett., 34, L16608, https://doi.org/10.1029/2007GL030302.

Chen, M. C., and T. Li, 2018: Why 1986 El Niño and 2005 La Niña evolved different from a typical El Niño and La Niña. Climate Dyn., 51, 4309-4327, https://doi.org/10.1007/s00382017-3852-1.

Chen, S. F., and R. Wu, 2017: An enhanced influence of sea surface temperature in the tropical northern Atlantic on the following winter ENSO since the early 1980s. Atmos. Oceanic Sci. Lett., 10, 175-182, https://doi.org/10.1080/16742834.2016. 1259542.

- , and B. Yu, 2020: The seasonal footprinting mechanism in large ensemble simulations of the second generation Canadian Earth System Model: Uncertainty due to internal climate variability. Climate Dyn., 55, 2523-2541, https://doi.org/ 10.1007/s00382-020-05396-y.

,-- , and W. Chen, 2014: An analysis on the physical process of the influence of AO on ENSO. Climate Dyn., 42, 973-989, https://doi.org/10.1007/s00382-012-1654-z.

— , R. Wu, and — , 2015: The changing relationship between interannual variations of the North Atlantic Oscillation and northern tropical Atlantic SST. J. Climate, 28, 485-504, https://doi.org/10.1175/JCLI-D-14-00422.1.

$\longrightarrow$, B. $\mathrm{Yu}, \longrightarrow$, and $\mathrm{R}$. $\mathrm{Wu}, 2018$ : A review of atmosphereocean forcings outside the tropical Pacific on the El Niño-
Southern Oscillation occurrence. Atmosphere, 9, 439, https:// doi.org/10.3390/atmos9110439.

$\longrightarrow$, R. Wu, and ——, 2019: Projections of climate changes over mid-high latitudes of Eurasia during boreal spring: Uncertainty due to internal variability. Climate Dyn., 53, 63096327, https://doi.org/10.1007/s00382-019-04929-4.

- W. Chen, R. Wu, B. Yu, and H. Graf, 2020a: Potential impact of preceding Aleutian low variation on the El Niño-Southern Oscillation during the following winter. J. Climate, 33, 3061-3077, https://doi.org/10.1175/JCLI-D-19-0717.1.

— , R. Wu, and W. Chen, 2020b: Strengthened connection between springtime North Atlantic Oscillation and North Atlantic tripole SST pattern since the late 1980s. J. Climate, 33, 2007-2022, https://doi.org/10.1175/JCLI-D-19-0628.1.

,,--- , and B. Yu, 2020c: Influence of winter Arctic sea ice concentration change on the El Niño-Southern Oscillation in the following winter. Climate Dyn., 54, 741-757, https://doi. org/10.1007/s00382-019-05027-1.

Chen, W., H. F. Graf, and R. Huang, 2000: The interannual variability of East Asian winter monsoon and its relation to the summer monsoon. Adv. Atmos. Sci., 17, 48-60, https://doi. org/10.1007/s00376-000-0042-5.

- J. Feng, and R. Wu, 2013: Roles of ENSO and PDO in the link of the East Asian winter monsoon to the following summer monsoon. J. Climate, 26, 622-635, https://doi.org/10.1175/ JCLI-D-12-00021.1.

Chiang, J. C. H., and D. J. Vimont, 2004: Analogous Pacific and Atlantic meridional modes of tropical atmosphere-ocean variability. J. Climate, 17, 4143-4158, https://doi.org/10.1175/ JCLI4953.1.

Chikamoto, Y., and Coauthors, 2015: Skillful multi-year predictions of tropical trans-basin climate variability. Nat. Commun., 6, 6869, https://doi.org/10.1038/ncomms7869.

- Z Z. Johnson, S. Wang, M. McPhaden, and T. Mochizuki, 2020: El Niño-Southern Oscillation evolution modulated by Atlantic forcing. J. Geophys. Res. Oceans, 125, e2020JC016318, https://doi.org/10.1029/2020JC016318.

Christian, J. R., and Coauthors, 2010: The global carbon cycle in the Canadian Earth system model (CanESM1): Preindustrial control simulation. J. Geophys. Res., 115, G03014, https://doi. org/10.1029/2008JG000920.

Curtis, S., and S. Hastenrath, 1995: Forcing of anomalous sea surface temperature evolution in the tropical Atlantic during Pacific warm events. J. Geophys. Res., 100, 15835-15847, https://doi.org/10.1029/95JC01502.

Czaja, A., P. Van der Vaart, and J. Marshall, 2002: A diagnostic study of the role of remote forcing in tropical Atlantic variability. J. Climate, 15, 3280-3290, https://doi.org/10.1175/15200442(2002)015<3280:ADSOTR >2.0.CO;2.

Dai, A., and T. M. L. Wigley, 2000: Global patterns of ENSOinduced precipitation. Geophys. Res. Lett., 27, 1283-1286, https://doi.org/10.1029/1999GL011140.

— , and C. E. Bloecker, 2019: Impacts of internal variability on temperature and precipitation trends in large ensemble simulations by two climate models. Climate Dyn., 52, 289-306, https://doi.org/10.1007/s00382-018-4132-4.

Deser, C., R. Knutti, S. Solomon, and A. S. Phillips, 2012: Communication of the role of natural variability in future North American climate. Nat. Climate Change, 2, 775-779, https:// doi.org/10.1038/nclimate1562.

- A. S. Phillips, M. A. Alexander, and B. V. Smoliak, 2014: Projecting North American climate over the next 50 years: 
Uncertainty due to internal variability. J. Climate, 27, 22712296, https://doi.org/10.1175/JCLI-D-13-00451.1.

- I. R. Simpson, K. A. McKinnon, and A. S. Phillips, 2017: The Northern Hemisphere extratropical atmospheric circulation response to ENSO: How well do we know it and how do we evaluate models accordingly? J. Climate, 30, 50595082, https://doi.org/10.1175/JCLI-D-16-0844.1.

Diaz, H. F., M. P. Hoerling, and J. K. Eischeid, 2001: ENSO variability, teleconnections and climate change. Int. J. Climatol., 21, 1845-1862, https://doi.org/10.1002/joc.631.

Ding, H., N. Keenlyside, and M. Latif, 2012: Impact of the equatorial Atlantic on the El Niño Southern Oscillation. Geophys. Res. Lett., 38, 1965-1972, https://doi.org/10.1007/s00382-0111097-y.

Ding, R. Q., J. Li, and Y. H. Tseng, 2015: The impact of South Pacific extratropical forcing on ENSO and comparisons with the North Pacific. Climate Dyn., 44, 2017-2034, https://doi. org/10.1007/s00382-014-2303-5.

,,,--- C. Sun, and F. Xie, 2017a: Joint impact of North and South Pacific extratropical atmospheric variability on the onset of ENSO events. J. Geophys. Res. Atmos., 122, 279298, https://doi.org/10.1002/2016JD025502.

,,,,---- and F. Zheng, 2017b: Linking a sea level pressure anomaly dipole over North America to the central Pacific El Niño. Climate Dyn., 49, 1321-1339, https://doi.org/ 10.1007/s00382-016-3389-8.

Ding, S., W. Chen, H.-F. Graf, Y. Guo, and D. Nath, 2017: Distinct winter patterns of tropical Pacific convection anomaly and the associated extratropical wave trains in the Northern Hemisphere. Climate Dyn., 51, 2003-2022, https://doi.org/10. 1007/s00382-017-3995-0.

Domeisen, D. I., C. I. Garfinkel, and A. H. Butler, 2019: The teleconnection of El Niño: Southern Oscillation to the stratosphere. Rev. Geophys., 57, 5-47, https://doi.org/10.1029/ 2018RG000596.

Duan, W., L. Song, Y. Li, and J. Mao, 2013: Modulation of PDO on the predictability of the interannual variability of early summer rainfall over south China. J. Geophys. Res. Atmos., 118, 13 008-13 021, https://doi.org/10.1002/2013JD019862.

Duchon, C. E., 1979: Lanczos filtering in one and two dimensions. J. Appl. Meteor., 18, 1016-1022, https://doi.org/10.1175/15200450(1979)018<1016:LFIOAT > 2.0.CO;2.

Fisher, R. A., 1921: On the "probable error" of a coefficient of correlation deduced from a small sample. Metron, 1, 3-32.

Furtado, J. C., E. D. Lorenzo, B. T. Anderson, and N. Schneider, 2012: Linkages between the North Pacific Oscillation and central tropical Pacific SSTs at low frequencies. Climate Dyn., 39, 2833-2846, https://doi.org/10.1007/s00382-011-1245-4.

Gray, W. M., 1984: Atlantic seasonal hurricane frequency. Part I: El Niño and $30 \mathrm{mb}$ quasi-biennial oscillation influences. Mon. Wea. Rev., 112, 1649-1668, https://doi.org/10.1175/15200493(1984)112<1649:ASHFPI > 2.0.CO;2.

Ham, Y.-G., and J.-S. Kug, 2015: Role of north tropical Atlantic SST on the ENSO simulated using CMIP3 and CMIP5 models. Climate Dyn., 45, 3103-3117, https://doi.org/10.1007/ s00382-015-2527-z.

- — - - J.-Y. Park, and F.-F. Jin, 2013: Sea surface temperature in the north tropical Atlantic as a trigger for El Niño/ Southern Oscillation events. Nat. Geosci., 6, 112-116, https:// doi.org/10.1038/ngeo1686.

He, S. P., and H. J. Wang, 2013: Oscillating relationship between the East Asian winter monsoon and ENSO. J. Climate, 26, 9819-9838, https://doi.org/10.1175/JCLI-D-13-00174.1.
Horel, J. D., and J. M. Wallace, 1981: Planetary-scale atmospheric phenomena associated with the Southern Oscillation. Mon. Wea. Rev., 109, 813-829, https://doi.org/10.1175/15200493(1981)109<0813:PSAPAW >2.0.CO;2.

Huang, B., and J. Shukla, 2005: Ocean-atmosphere interactions in the tropical and subtropical Atlantic Ocean. J. Climate, 18, 1652-1672, https://doi.org/10.1175/JCLI3368.1.

_ , and Coauthors, 2017: Extended Reconstructed Sea Surface Temperature version 5 (ERSSTv5): Upgrades, validations, and intercomparisons. J. Climate, 30, 8179-8205, https://doi. org/10.1175/JCLI-D-16-0836.1.

Huang, R., R. Zhang, and B. Yan, 2001: Dynamical effect of the zonal wind anomalies over the tropical western Pacific on ENSO cycles. Sci. China, 44D, 1089-1098, https://doi.org/10. 1007/BF02906865.

— W W. Chen, B. Yang, and R. Zhang, 2004: Recent advances in studies of the interaction between the East Asian winter and summer monsoons and ENSO cycle. Adv. Atmos. Sci., 21, 407-424, https://doi.org/10.1007/BF02915568.

Hurrell, J. W., and H. van Loon, 1997: Decadal variations in climate associated with the North Atlantic Oscillation. Climatic Change at High Elevation Sites, H. F. Diaz, M. Beniston, and R. Bradley, Eds., Springer, 69-94.

Izumo, T., and Coauthors, 2010: Influence of the state of the Indian Ocean dipole on the following year's El Niño. Nat. Geosci., 3, 168-172, https://doi.org/10.1038/ngeo760.

— J. Vialard, H. Dayan, M. Lengaigne, and I. Suresh, 2016: A simple estimation of equatorial Pacific response from windstress to untangle Indian Ocean Dipole and Basin influences on El Niño. Climate Dyn., 46, 2247-2268, https://doi.org/10. 1007/s00382-015-2700-4.

Jia, F., L. Wu, B. L. Gan, and W. Cai, 2016: Global warming attenuates the tropical Atlantic-Pacific teleconnection. Sci. Rep., 6, 20078, https://doi.org/10.1038/srep20078.

— W. Wai, L. Wu, B. L. Gan, G. Wang, F. Kucharhi, P. Chang, and N. Keenlyside, 2019: Weakening Atlantic Niño-Pacific connection under greenhouse warming. Sci. Adv., 5, eaax4111, https://doi.org/10.1126/sciadv.aax4111.

Jia, X. J., S. Wang, H. Lin, and Q. Bao, 2015: A connection between the tropical Pacific Ocean and the winter climate in the Asian-Pacific region. J. Geophys. Res. Atmos., 120, 430448, https://doi.org/10.1002/2014JD022324.

— J. W. Ge, and S. Wang, 2016: Diverse impacts of ENSO on wintertime rainfall over the Maritime Continent. Int. J. Climatol., 36, 3384-3397, https://doi.org/10.1002/joc.4562.

Jin, F. F., 1997: An equatorial ocean recharge paradigm for ENSO. Part I: Conceptual model. J. Atmos. Sci., 54, 811-829, https://doi.org/10.1175/1520-0469(1997)054<0811: AEORPF $>2.0 . \mathrm{CO} ; 2$.

Johnson, Z., Y. Chikamoto, S. Wang, M. McPhaden, and T. Mochizuki, 2020: Pacific Decadal Oscillation remotely forced by the equatorial Pacific and Atlantic Oceans. Climate Dyn., 55, 789-811, https://doi.org/10.1007/s00382-020-05295-2.

Joshi, M. K., and K. J. Ha, 2019: Fidelity of CMIP5-simulated teleconnection between Atlantic multidecadal oscillation and Indian summer monsoon rainfall. Climate Dyn., 52, 41574176, https://doi.org/10.1007/s00382-018-4376-Z.

Kalnay, E., and Coauthors, 1996: The NCEP/NCAR 40-Year Reanalysis Project. Bull. Amer. Meteor. Soc., 77, 437-471, https://doi.org/10.1175/1520-0477(1996)077<0437:TNYRP>2. $0 . \mathrm{CO} ; 2$.

Kay, J. E., and Coauthors, 2015: The Community Earth System Model (CESM) large ensemble project: A community resource 
for studying climate change in the presence of internal climate variability. Bull. Amer. Meter. Soc., 96, 1333-1349, https://doi. org/10.1175/BAMS-D-13-00255.1.

Keenlyside, N. S., H. Ding, and M. Latif, 2013: Potential of equatorial Atlantic variability to enhance El Niño prediction. Geophys. Res. Lett., 40, 2278-2283, https://doi.org/10.1002/grl. 50362.

Kirchmeier-Young, M. C., F. W. Zwiers, and N. P. Gillett, 2017: Attribution of extreme events in Arctic sea ice extent. J. Climate, 30, 553-571, https://doi.org/10.1175/JCLI-D-16-0412.1.

Kucharski, F., I. Kang, R. Farneti, and L. Feudale, 2011: Tropical Pacific response to 20th century Atlantic warming. Geophys. Res. Lett., 38, L0302, https://doi.org/10.1029/2010GL046248.

— , and Coauthors, 2016: Atlantic forcing of Pacific decadal variability. Climate Dyn., 46, 2337-2351, https://doi.org/10.1007/ s00382-015-2705-z.

Larson, S., and B. Kirtman, 2013: The Pacific meridional mode as a trigger for ENSO in a high-resolution coupled model. Geophys. Res. Lett., 40, 3189-3194, https://doi.org/10.1002/grl. 50571.

Lengaigne, M., E. Guilyardi, J. P. Boulanger, C. Menkes, P. Delecluse, P. Inness, J. Cole, and J. Slingo, 2004: Triggering of El Niño by westerly wind events in a coupled general circulation model. Climate Dyn., 23, 601-620, https://doi.org/10.1007/ s00382-004-0457-2.

Li, X., S. Xie, S. Gille, and C. Yoo, 2015: Atlantic-induced pantropical climate change over the past three decades. Nat. Climate Change, 6, 275-279, https://doi.org/10.1038/nclimate2840.

Linkin, M. E., and S. Nigam, 2008: The North Pacific Oscillation-west Pacific teleconnection pattern: Mature-phase structure and winter impacts. J. Climate, 21, 1979-1997, https://doi. org/10.1175/2007JCLI2048.1.

Ma, T., W. Chen, D. Nath, H.-F. Graf, L. Wang, and J. Huangfu, 2018: East Asian winter monsoon impacts the ENSO-related teleconnections and North American seasonal air temperature prediction. Sci. Rep., 8, 6547, https://doi.org/10.1038/ s41598-018-24552-3.

$\longrightarrow,-$, H.-F. Graf, S. Ding, P. Xu, L. Song, and X. Lan, 2020: Different impacts of the East Asian winter monsoon on the surface air temperature in North America during ENSO and neutral ENSO years. J. Climate, 33, 10 671-10 690, https://doi. org/10.1175/JCLI-D-18-0760.1.

Maher, N., D. Matei, S. Milinski, and J. Marotzke, 2018: ENSO change in climate projections: Forced response or internal variability? Geophys. Res. Lett., 45, 11390-11398, https://doi. org/10.1029/2018GL079764.

— , and Coauthors, 2019: The Max Planck Institute grand ensemble: Enabling the exploration of climate system variability. J. Adv. Model. Earth Syst., 11, 2050-2069, https://doi. org/10.1029/2019MS001639.

Martín-Rey, M., B. Rodríguez-Fonseca, I. Polo, and F. Kucharski, 2014: On the Atlantic-Pacific Niños connection: A multidecadal modulated mode. Climate Dyn., 43, 3163-3178, https:// doi.org/10.1007/s00382-014-2305-3.

,-- , and -2015 : Atlantic opportunities for ENSO prediction. Geophys. Res. Lett., 42, 6802-6810, https://doi.org/10. 1002/2015GL065062.

— I. Polo, B. Rodríguez-Fonseca, T. Losada, and A. Lazar, 2018: Is there evidence of changes in tropical Atlantic variability modes under AMO phases in the observational record? J. Climate, 31, 515-536, https://doi.org/10.1175/JCLID-16-0459.1.
McPhaden, M. J., S. E. Zebiak, and M. H. Glantz, 2006: ENSO as an integrating concept in Earth science. Science, 314, 1740 1745, https://doi.org/10.1126/science.1132588.

Min, Q., J. Su, and R. Zhang, 2017: Impact of the South and North Pacific meridional modes on the El Niño-Southern Oscillation: Observational analysis and comparison. J. Climate, 30, 1705-1720, https://doi.org/10.1175/JCLI-D-16-0063.1.

Nakamura, T., Y. Tachibana, M. Honda, and S. Yamane, 2006: Influence of the Northern Hemisphere annular mode on ENSO by modulating westerly wind bursts. Geophys. Res. Lett., 33, L07709, https://doi.org/10.1029/2005GL025432.

,-- , and H. Shimoda, 2007: Importance of cold and dry surges in substantiating the NAM and ENSO relationship. Geophys. Res. Lett., 34, L22703, https://doi.org/10.1029/ 2007GL031220.

Neelin, J. D., D. S. Batiste, A. C. Hirst, F. F. Jin, Y. Wakata, T. Yamagata, and S. E. Zebiak, 1998: ENSO theory. J. Geophys. Res., 103, 14261-14290, https://doi.org/10.1029/97JC03424.

Pan, L.-L., 2005: Observed positive feedback between the NAO and the North Atlantic SSTA tripole. Geophys. Res. Lett., 32, L06707, https://doi.org/10.1029/2005GL022427.

Park, J. H., and T. Li, 2019: Interdecadal modulation of El Niño-tropical North Atlantic teleconnection by the Atlantic multi-decadal oscillation. Climate Dyn., 52, 5345-5360, https:// doi.org/10.1007/s00382-018-4452-4.

,-- , S. W. Yeh, and H. Kim, 2019: Effect of recent Atlantic warming in strengthening Atlantic-Pacific teleconnection on interannual timescale via enhanced connection with the Pacific meridional mode. Climate Dyn., 53, 371-387, https:// doi.org/10.1007/s00382-018-4591-7.

— , S. An, J. S. Kug, Y. M. Yang, T. Li, and H. S. Jo, 2021: Mid-latitude leading double-dip La Niña. Int. J. Climatol., 41, E1353-E1370, https://doi.org/10.1002/joc.6772.

Peng, S., W. A. Robinson, and S. Li, 2003: Mechanisms for the NAO responses to the North Atlantic SST tripole. J. Climate, 16, 1987-2004, https://doi.org/10.1175/1520-0442(2003)016<1987: MFTNRT $>2.0 . \mathrm{CO} ; 2$.

Piao, J., W. Chen, and S. Chen, 2021: Sources of the internal variability-generated uncertainties in the projection of Northeast Asian summer precipitation. Climate Dyn., 56, 1783-1797, https://doi.org/10.1007/s00382-020-05557-z.

Quan, M. Y., X. D. Wang, G. D. Zhou, K. Fan, and Z. He, 2020: Effect of winter-to-summer El Niños transitions on tropical cyclone activity in the North Atlantic. Climate Dyn., 54, 1683-1698, https://doi.org/10.1007/s00382-019-05081-9.

Rayner, N. A., and Coauthors, 2003: Global analyses of sea surface temperature, sea ice, and night marine air temperature since the late nineteenth century. J. Geophys. Res., 108, 4407, https://doi.org/10.1029/2002JD002670.

Rodríguez-Fonseca, B., I. Polo, J. García-Serrano, T. Losada, E. Mohino, C. Mechoso, and F. Kucharski, 2009: Are Atlantic Niños enhancing Pacific ENSO events in recent decades? Geophys. Res. Lett., 36, L20705, https://doi.org/10.1029/ 2009GL040048.

Ruprich-Robert, Y., R. Msadek, F. Castruccio, S. Yeager, T. Delworth, and G. Danabasoglu, 2017: Assessing the climate impacts of the observed Atlantic multidecadal variability using the GFDL CM2.1 and NCAR CESM1 global coupled models. J. Climate, 30, 2785-2810, https://doi.org/10.1175/ JCLI-D-16-0127.1.

Sigmond, M., and J. C. Fyfe, 2016: Tropical Pacific impacts on cooling North American winters. Nat. Climate Change, 6, 970-974, https://doi.org/10.1038/nclimate3069. 
Song, L., Y. Li, and W. Duan, 2016a: The influence of boreal winter extratropical North Pacific Oscillation on Australian spring rainfall. Climate Dyn., 47, 1181-1196, https://doi.org/10. 1007/s00382-015-2895-4.

_ W. Duan, Y. Li, and J. Mao, 2016b: A timescale decomposed threshold regression downscaling approach to forecasting South China early summer rainfall. Adv. Atmos. Sci., 33, 1071-1084, https://doi.org/10.1007/s00376-016-5251-7.

—, S. F. Chen, W. Chen, and X. Chen, 2017: Distinct impacts of two types of La Niña events on Australian summer rainfall. Int. J. Climatol., 37, 2532-2544, https://doi.org/10.1002/joc. 4863.

Suarez, M. J., and P. S. Schopf, 1988: A delayed action oscillator for ENSO. J. Atmos. Sci., 45, 3283-3287, https://doi.org/10. 1175/1520-0469(1988)045<3283:ADAOFE >2.0.CO;2.

Trenberth, K. E., G. W. Branstator, D. Karoly, A. Kumar, N. C. Lau, and C. Ropelewski, 1998: Progress during TOGA in understanding and modeling global teleconnections associated with tropical sea surface temperatures. J. Geophys. Res., 103, 14291-14324, https://doi.org/10.1029/97JC01444.

van Vuuren, D. P., and Coauthors, 2011: The representative concentration pathways: An overview. Climatic Change, 109, 531, https://doi.org/10.1007/s10584-011-0148-z.

Vimont, D. J., D. S. Battisti, and A. C. Hirst, 2001: Footprinting: A seasonal connection between the tropics and mid-latitudes. Geophys. Res. Lett., 28, 3923-3926, https://doi.org/10.1029/ 2001GL013435.

—, J. M. Wallace, and D. S. Battisti, 2003: The seasonal footprinting mechanism in the Pacific: Implications for ENSO. $J$. Climate, 16, 2668-2675, https://doi.org/10.1175/15200442(2003)016<2668:TSFMIT>2.0.CO;2.

Wallace, J. M., and D. S. Gutzler, 1981: Teleconnections in the geopotential height field during the Northern Hemisphere winter. Mon. Wea. Rev., 109, 784-812, https://doi.org/10.1175/ 1520-0493(1981)109<0784:TITGHF > 2.0.CO;2.

, C. Deser, B. V. Smoliak, and A. S. Phillips, 2015: Attribution of climate change in the presence of internal variability. Climate Change: Multidecadal and Beyond. C. P. Chang et al., Eds., Asia-Pacific Weather and Climate Series, Vol. 6, World Scientific, 1-29, https://doi.org/10.1142/9789814579933_0001.
Wang, B., R. Wu, and X. Fu, 2000: Pacific-East Asian teleconnection: How does ENSO affect East Asian climate? J. Climate, 13, 1517-1536, https://doi.org/10.1175/1520-0442(2000)013< 1517:PEATHD > 2.0.CO;2.

Wang, L., J. Yu, and H. Paek, 2017: Enhanced biennial variability in the Pacific due to Atlantic capacitor effect. Nat. Commun., 8, 14887, https://doi.org/10.1038/ncomms14887.

Wang, X., C. Guan, R. Huang, W. Tan, and L. Wang, 2019: The roles of tropical and subtropical wind stress anomalies in the El Niño Modoki onset. Climate Dyn., 52, 6585-6597, https:// doi.org/10.1007/s00382-018-4534-3.

Wu, L., and Z. Liu, 2005: North Atlantic decadal variability: Air-sea coupling, oceanic memory, and potential Northern Hemisphere resonance. J. Climate, 18, 331-349, https://doi.org/10. 1175/JCLI-3264.1.

Xie, S. P., and S. G. H. Philander, 1994: A coupled ocean-atmosphere model of relevance to the ITCZ in the eastern Pacific. Tellus, 46A, 340-350, https://doi.org/10.3402/tellusa.v46i4.15484.

Yang, Y., and L. X. Wu, 2015: Changes of air-sea coupling in the North Atlantic over the 20th century. Adv. Atmos. Sci., 32, 445-456, https://doi.org/10.1007/s00376-014-4090-7.

Yeh, S.-W., and Coauthors, 2018: ENSO atmospheric teleconnections and their response to greenhouse gas forcing. Rev. Geophys., 56, 185-206, https://doi.org/10.1002/2017RG000568.

Yu, B., and F. Zwiers, 2007: The impact of combined ENSO and PDO on the PNA climate: A 1,000-year climate modeling study. Climate Dyn., 29, 837-851, https://doi.org/10.1007/ s00382-007-0267-4.

— , G. L. Li, S. F. Chen, and H. Lin, 2020: The role of internal variability in climate change projections of North American surface air temperature and temperature extremes in CanESM2 large ensemble simulations. Climate Dyn., 55, 869-885, https://doi.org/10.1007/s00382-020-05296-1.

Zhao, W., S. F. Chen, W. Chen, S. Yao, D. Nath, and B. Yu, 2019: Interannual variations of the rainy season withdrawal of the monsoon transitional zone in China. Climate Dyn., 53, 2031-2046, https://doi.org/10.1007/s00382-019-04762-9.

Zheng, Y. Q., S. F. Chen, W. Chen, and B. Yu, 2021: Diverse influences of spring Arctic Oscillation on the following winter El Niño-Southern Oscillation in CMIP5 models. Climate Dyn., 56, 275-297, https://doi.org/10.1007/s00382-020-05483-0. 